\title{
Sobre el Portugal ilustrado
}

\author{
laura santolaya Heredero *
}

El mismo título invita a preguntarse, a modo de introducción, en qué consistió la llustración en Portugal. Me refiero a las prácticas, sin pretender entrar en un debate filosófico.

Desde luego, las prácticas políticas y económicas de los Estados del xvilı poco tuvieron que ver con las ideas de los filósofos de la llustración.

El fenómeno de la llustración se aprovechó de una propaganda anecdótica para hacer suponer a los lectores de libros sobre ella que en los diversos Estados de Europa se habia producido un cambio.

Me atrevo a decir que no hubo tal cambio con respecto a los planteamientos, por ejemplo políticos, del siglo xvII sino, en todo caso, un perfeccionamiento de los procedimientos externos, uno de cuyos puntos claves era la necesidad de conocer, por parte de los gobernantes, lo que se gobernaba (geografía, límites, individuos y haciendas) para una mayor recaudación fiscal, punto éste fundamental para fortalecer el Estado absoIuto.

La misma palabra alemana Aufklärung en la segunda mitad del xVIII tenía el significado de «esclarecer», «descubrir», «hacer claro» algo oscuro. Si llustración era «claridad» podría decirse que hubo un intento de alcanzar la misma por parte de los gobiernos pero con un sentido físico, sin que supusiera ningún cambio profundo.

Quedaba cuestionado, por tanto, el concepto de llustración como un supuesto revulsivo para modificar el status de las monarquías. Más bien se trataba de un modo nuevo de fortificar la realidad existente. Debería extenderse a todos los campos: desde la religión a la moral, a la politica, a la economía, a la educación o a la beneficencia, y todo ello animado

\footnotetext{
* Profesora Titular de Historia Moderna. UNED.
} 
por una permanente crítica a lo oscuro, «a lo nuboso». El reinado de José I (1750-1777) fue el período ilustrado por excelencia de Portugal. En él se produjo, ante todo, el fortalecimiento de la monarquia.

Tuvo dicho reinado la suerte de contar con un ministro como Pombal que se dedicó simplemente a quitar obstáculos que impidieran dicho fortalecimiento. Ello no significó por parte del rey, o por parte de Pombal, un cambio hacia una nueva realidad, hacia algo más liberal. Esteves Pereira escribe: «El príncipe que se dice ilustrado no es un liberal, un reformador filantrópico a quien le obcecan la Razón, el amor a los hombres - la sed de justicia. Sin embargo, sin la corriente racionalista de fin del xVII y sin las complicidades "filosóficas» de la edad de las luces, es probable que el Despotismo llustrado no hubiera encontrado ni su doctrina, ni un estilo ni las formas indispensables a una irradiación secular».

Cierto es que la figura de Pombal se benefició de la historiografía del siglo XIX al estar interesados los liberales y republicanos portugueses en presentar sus reformas como revolucionarias o pre-revolucionarias intentando dar a la nueva era un aire de continuidad. Todo ello contribuyó a formar una peculiar imagen del ministro por la cual éste habria sido un perfecto pre-liberal o puente entre el absolutismo y el liberalismo.

Hay que volver a un razonamiento general: conceptos como razón o luces fueron la insignia de los monarcas europeos para aumentar la riqueza de sus territorios a fin de presentarse ante las demás monarquias de Europa en posición favorable. En la misma España, la consentida decadencia de la Mesta, el sometimiento de la Inquisición a la monarquía, el débil intento de ataque a los bienes de la Iglesia, la aplicación del regalismo, por ejemplo, no fueron medidas pre-liberales sino fórmulas de reforzamiento del poder. Por otra parte, para gobernar era preciso crear un ambiente de paz social; de ahí todos los esfuerzos de reformas que llamo secundarias, encaminadas a no crear descontentos: higiene, hospitales, mejoras de las vias públicas, etc.

A los reyes los hicieron verdaderamente ilustrados sus historiadores. Estos fueron los que a las reformas llamaron ilustradas y los que relataron y alabaron las reformas secundarias, en tanto que las primarias (ias que podian anunciar una nueva sociedad: igualdad, libertad, propiedad) quedaban relegadas y fuera de los libros, pero es que ni fueron abordadas ni habia pretensión de hacerlo.

Se ha hablado mucho del pombalismo como un fenómeno especial. Con todo fue un resultado de lo acabado de señalar, como en España fue el «carlotercerismo». Por eso, y ya que nos ceñimos a una persona, lo que habria que preguntar es si Pombal fue moderno o no, o si planteó soluciones modernas. 
Las fórmulas utilizadas por esclarecer Portugal era sabidas. Juan Lucio de Azevedo - uno de los primeros historiadores de Pombal y su época- escribía: «Ninguna de las grandes ideas que agitaban a los cerebros pensantes de Europa, halló acogida en él. Fue a buscar los modelos más de cien años atrás. En asuntos económicos tuvo por maestro a Sully; en política tomó por guía a Richelieu». Pero sería de éste tan sólo su aspecto de la razón de Estado, porque por lo demás siguió la estricta filosofía política del absolutismo ${ }^{1}$.

Algunos historiadores, defensores de un Pombal ilustrado, quieren ver una especie de contradicción interpretativa cuando observan que ciertos procederes y realizaciones no pueden ser consideradas como ilustradas. Habría vivido Pombal, para éstos, en contradicción muy a pesar suyo. A nuestro juicio, Pombal no vivió en contradicción, actuó simplemente intentando potenciar la monarquía portuguesa.

Esteves Pereira indica que el problema del pombalismo es que tradicionalmente ha aparecido dotado de un aperturismo. Pombal ha quedado en la Historia como un personaje que rompió moldes. En esta ruptura de moldes se trae enseguida a colación la expulsión de la Compañia de Jesús como un hecho total, sin mayores explicaciones.

Pudo tener una cierta ideología racionalista que enseguida se vinculó a un aspecto, el pombalismo cultural. Sin embargo, fue, ante todo, un hacer y una práctica, que se rodeó de un cierto halo heterodoxo. No hay que olvidar, por otro lado, que los juicios y decisiones de Pombal fueron permanentemente pretendidos: fue un policia de la cultura para dominar el aparato ideológico del Estado y luego, el mismo Estado.

Esto hace comprender, por ejemplo, la prohibición de libros de 24 de septiembre de 1770 . Por eso, resulta dificil entender en el Pombalismo la conciliación entre el "programa de apertura filosófica» y la necesidad de apoyar a la Corona siguiendo los principios del absolutismo más cerrado ${ }^{2}$.

Ribeiro dos Santos, defensor de la permanente contradicción de Pombal, escribía: «Este ministro pretendió un imposible político; quiso civilizar a la nación y al mismo tiempo hacerla esclava; quiso resaltar la luz de las ciencias filosóficas y al mismo tiempo elevar el poder real al despotismo; inculcó el estudio del derecho natural y de gentes (...) pero no dio

\footnotetext{
Pereira, M. B., "llustración y secularización», en VV.AA., O Marquês de Pombal e o suo tempo. Coimbra 1982-83, 2 vols., II, págs. 439 y ss.

2 Esteves PerelRA, J., O pensamento politico em Portugal no seculo xvill (Antonio Ribeiro dos Santos). Lisboa 1983, págs. 75-93
} 
luces a los pueblos para conocer que el poder soberano estaba únicamente establecido para el bien de la nación y no del principe...». Esto último tampoco lo intentó, fiel al principio de «con el pueblo pero sin el pueblo" ${ }^{3}$.

He esbozado hasta aquí la respuesta a la cuestión general sobre la Ilustración y Portugal. Ahora voy a centrarme en exponer lo que considero fundamental para entender este periodo ilustrado: se trató de fortalecer el poder de la monarquía. Pombal orientará a José I a fortalecer "su» monarquía tanto en el interior como en el exterior; en este caso se tratará de presentar una imagen aceptable ante los demás Estados europeos.

Fortalecer el poder de la monarquía suponía, en el plano teórico, atender a unas reglas en los tres campos tradicionales de política, economía y sociedad.

En política habia dos fuerzas en lucha: el absolutismo y el curialismo. Triunfó el primero que significaba, con el regalismo, la supremacia del poder regio sobre la Iglesia de Roma; o venció una religión del Estado, que era institucional y objetiva, a la verdadera piedad subjetiva tal como lo expresaba Cabral de Moncada. Se trataba de alcanzar la independencia definitiva de la Monarquía.

El mismo pensamiento de Pereira da Figueiredo, según constata DaSilva Dias, como defensor del Estado, se movió exclusivamente en el plano de las relaciones Estado-Iglesia intentando justificar la autonomía del primero y la incompetencia de la segunda fuera del campo puramente espiritual. Lo cual no era novedoso porque la pugna venía de décadas atrás.

Rompia Pereira con la visión de la sociedad civil a imagen y semejanza de la sociedad eclesiástica; y rompia, en consecuencia, la visión del Estado como brazo secular de la Iglesia.

Analizaba, por otro lado, el poder temporal como un poder autónomo e independiente del poder espiritual, emanado directamente de Dios para el rey, y con ello excluía todas las veleidades de apropiación teocrática por parte de la Iglesia, Omnis potestas a Deo per Papam o democráticas de la comunidad, Omnis potestas a Deo per populum.

Por ser autónomo y supremo, el poder regio no podia ser tutelado e inspeccionado por el poder espiritual. En consecuencia, constituiría un acto político ilícito toda tentativa de censura o destitución del rey tanto por el papado como por la comunidad civil. La autoridad regia solamente

3 Ibidem, id. 
estaba limitada por Dios, lo que quería decir que solamente por la propia conciencia del monarca.

Esto significaba, también, en la práctica que la realeza tenía el control de las entidades y de las estructuras eclesiásticas, y la subordinación de la Iglesia y de sus clérigos en todo lo tocante a las llamadas temporalidades. Éstas reunian los bienes inmuebles y muebles, la respetada obediencia a las leyes civiles, la sujeción a los tribunales civiles y el pago de los tributos civiles. Implicaba, asímismo, la administración del patrimonio eclesial y el derecho de veto a la hora de escoger los prelados y los párracos para la cura de almas.

Separar a la monarquía del poder eclesiástico era tan sólo el inicial punto obligado para reforzar el absolutismo.

Dicho absolutismo pasaba por acabar con todo tipo de iusnaturalismo porque se trataba de lograr para el mismo una fórmula dura. Por supuesto, en este trance se vio involucrada la Compañia de Jesús por ser, ante todo, defensora de la escuela escolástica democrática mucho más que por ser representante del curialismo ultramontano. El mismo Suárez había señalado que la forma de establecimiento de la monarquía era el consentimiento popular ${ }^{4}$.

Por eso, Pombal, al expulsarla, logró además de otras muchas cosas, acabar con cualquier veleidad casuistica en relación con el poder civil.

Una vez sustentada la independencia, era preciso establecer una teoría de este absolutismo. Ribeiro dos Santos fue su pensador político.

Para él, el poder real tenía su origen en Dios y su ejercicio no sufria ninguna limitación, salvo la divina. Sus obligaciones comprendian: el derecho de legislar, el de juzgar, de nombrar magistrados y decidir la guerra y la paz. Sobre esta base, el absolutismo pombalino intentó llegar a una sociedad natural a través de una transformación social, política, mental y económica, apoyada en un sujeto activo mercantilista, y toda ella dirigida por la voluntad política y legal del Estado.

Según Esteves Pereira en este planteamiento de Ribeiro el súbdito quedaba dentro de este poder de modo que cogía incluso a las propiedades de aquél en términos de su uso y dominio.

El Príncipe tenía un derecho eminente sobre los bienes de los súbditos: podía usarlos, por enajenación o destrucción, conforme a las exigencias del Estado en ese momento.

"Da Silva Dias, J. S., "Pombalismo y teoría política”, Cultura, vol. I, (1982), págs. 25-30. 
El derecho, en última instancia, podía decidir en casos de herencia de las últimas voluntades de los súditos, rescindir los testamentos sin valor, apoderarse de las tierras para provecho de las ciudades o para la construcción de obras públicas que interesaran a la república, en especial en caso de defensa del territorio.

En la obra de Ribeiro De Sacerdotio et Imperio se exigía al súbdito una obediencia que podia compararse a la pretendida por Lutero o Calvino: debía amar al Príncipe, rezar por él, obedecerle y conservar la fe que se le debía como guardián de la misma. Esta obediencia y por delegación a sus ministros, debia entenderse como un rechazo a cualquier subjetividad dejando siempre que triunfara la voluntad regia absoluta; de ahi que Ribeiro considerara falsa la tesis de que las leyes civiles no obligan en conciencia.

Esta fundamentación filosófica-teológica del poder servia para atacar la tesis monarcómanas de Vindiciae contra Tyrannos de Plessis-Mornay y Languet, de la Franco-galia de Hotman, del pensamiento de Althusius y de las ideas del jesuita Mariana.

Asi, Ribeiro aprovechó para expurgar obras de jesuitas: De rege e regis institutione (1605), de Mariana, De auctoritate Summi Pontificis (1610) de Belarmino, o Defensio Fidei Catholicae (1614) de Suárez.

Para Ribeiro, el poder de la Iglesia debia ejercerse sobre los hombres en un nivel de consideración ética y no política. Debía aquélla castigar los vicios, no a los hombres; lo que suponia una forma de control éticojurisdiccional evidente por parte del Estado.

El sacerdocio debía sujetarse en el orden político al imperio, del mismo modo que reservaba para sí el ordenamiento moral que el Estado, en principio, debía acatar. Esto le llevaba a concluir que la admisión y conservación de las órdenes religiosas, iglesias, universidades... dependian exclusivamente de la autoridad del Príncipe.

Por tanto, dicho regalismo, basado en el pragmatismo diario, podía indicar que para la salvación de la república era necesario en un determinado momento prohibir ciertas instituciones.

La Iglesia, según habia defendido Gerson, Juan de París y Pedro de Marca, puso, en su día, los bienes eclesiásticos «bajo el derecho de los reyes». Esta dependencia al Estado daba la posibilidad de la enajenación de los mismos por parte del Príncipe, en caso de que fuese necesario para la República.

Los reyes, por derecho de protección, debian extirpar cualquier abuso religioso o canónico, obligar a los eclesiásticos a los ejercicios propios sacerdotales (los jesuitas, por ejemplo, serían atacados, además, por 
abarcar otros campos), reprimir la contumacia de los obispos y del clero en general, intervenir en las sentencias sinodales, reprimir a los heréti$\cos . . . y$, de modo general, intervenir en todo lo concerniente a lo que era pura materia judicial de la iglesia ${ }^{5}$.

Ribeiro se sustentó en Bodino y avanzó, teniendo en cuenta la sociedad burguesa mercantilista, a las posiciones de Hobbes. Éste hacía posible una sociedad liberal pero para que ésta fuera así construyó una soberania en forma de poder absoluto.

Sustentada la monarquía en la teoría política, era preciso entrar en lo económico y social. Lo cual era ya una realidad. Pombal puso su punto de mira en la nobleza, para atraerla a sus programas y, a su vez, incitó a la burguesía a seguir estos mismos programas con una promesa de nobleza. De hecho, cuando intentó reunir comerciantes privilegiados para sus Compañías monopolísticas, los fue a buscar -como escribe Borges de Macedo- entre la clase noble. A su vez, a los grandes comerciantes burgueses los convirtió por sus servicios en nobles, directamente o por casamiento. Si se examinan los privilegios de las Compañias o las recompensas concedidas a los miembros de los organismos creados, se encuentra que la nobleza es tratada con la máxima consideración.

Pombal apoyó a la nobleza como estamento pero no a determinados sujetos de la nobleza. La lucha entre facciones no significaba el aniquilamiento de la clase porque había que distinguir entre la posición social de ésta y la posición política de una facción de la misma.

Lo dicho es necesario para entender que hubo una nobleza que estaba de acuerdo con los intereses de la monarquía y que hubo otra que fue perseguida.

Una cosa parece indiscutible: la legislación consagró la influencia social de la nobleza como clase, hasta el punto de darle unas nuevas formas de comportamiento. En este tiempo, la nobleza estuvo ligada al propio aparato del Estado, y ello no en función exclusiva de sus privilegios sino simplemente en función de la propia máquina del Estado y de su organización interna. Además, ninguna otra política social podia concebirse en un Estado basado económicamente en el monopolio y políticamente «en la ciencia cierta y en el poder absoluto del rey". Los grupos provilegiados se garantizaban en el Estado y el Estado se garantizaba en los grupos privilegiados.

Los estatutos de la nobleza no fueron relegados sino integrados en la orgánica del Estado como una institución con plena eficiencia social. Por

\footnotetext{
${ }^{5}$ Esteves Pereira, J., op. cit. , págs. 95 y ss.
} 
la ley de 29 de noviembre de 1775, al fin de la época pombalina, el comerciante al por mayor - lo que significaba el gran monopolista-, el que estaba vinculado con las grandes compañías, adquiría el fuero de hidalgo y tenía acceso exclusivo, en relación con los otros comerciantes, a la propiedad vinculada.

Fueron entrando en la nobleza apellidos vinculados con el gran comercio. En el fondo, no se olvide, era un intento de reforzar el comercio que era lo que interesaba: para ello, se contaba la nobleza como status social a alcanzar y se daban actas de nobleza a los que invirtieran una determinada cantidad.

Por eso, el ataque de Pombal a una facción de la clase nobiliaria en absoluto implicaba ir contra la clase en general, por el contrario, era un intento de reconvertir a la nobleza a los propios fines. Lo que hizo fue romper ciertos predominios politicos en provecho de otros.

La integración de la nobleza en el Estado fue aprovechada por éste para combatir a los jesuitas que habian estado vinculados a ella. Los jesuitas, escribe Borges de Macedo, estaban dando importancia a una actividad ajena a ellos, la económica, además de su proceder misionero ${ }^{5}$.

El mensaje de Pombal consistió en presentar a unos jesuitas poderosos que podian frenar los planteamientos que el Estado habia reservado a la nobleza y a la alta burguesía como principales protagonistas de sus intereses. Los jesuitas, por otra parte, aparecian con una política externa y con una influencia internacional, independiente del Estado al que estaban adscritos, que provocaba en el Estado portugués, una especie de situación intolerable de cara a su gobierno.

Si a eso se añade que los jesuitas declaraban una subordinación a Roma, que chocaba con el regalismo, el efecto les convertia en elementos peligrosos.

Hay que añadir, antes de entrar en una explicación de lo dicho, que en el estricto campo de la economía el Estado portugués apenas inventó nada. $\mathrm{O}$, mejor, se movió en esquemas del momento. Pombal fue un colbertista tardio que favoreció las manufacturas y las fábricas reales a la vez que se encontraba con una etapa de fuerte llegada de metal precioso de Brasil. Por lo tanto, no atendió a la importante masa de la pobiación que dependia de la tierra. Algunos historiadores le han achacado que no fue fisiócrata, pero tal doctrina no iba de acuerdo con las pretensiones

\footnotetext{
6 Borges de Macedo, J., A situaçao económica no tempo de Pombal, 3 ed. Lisboa 1989, pág. 116.
} 
políticas y sociales, por un lado porque no resultaba de fácil aplicación en un territorio de baja calidad $y$, por otro, porque la fuente económica no estaba en la península sino en las colonias y, principalmente, en Brasil.

De ahi el fomento de las Compañías comerciales. El asunto no era nuevo; éstas habian venido desarrollándose, con gran fruto, desde principios del siglo xvil. Pero el esquema de una red de compañías paraestatal podia poner en orden lo único que convenía a Portugal: la llegada permanente de recursos.

Por eso, el conjunto de reformas portuguesas podría resumirse en un movimiento centralista en favor de un Estado fuerte. La creación del Erario Regio, de la Junta de Comercio que regulaba a las Compañias, de la Intendencia de Policia, de la Real Mesa de Censura, la reestructuración de la Inquisición (en favor de la Corona), la reforma de la Universidad y la fundación de los Estudios Menores bajo la dependencia del Estado, así como la formación de la Imprenta Real y de la Imprenta de la Universidad, la elaboración de una legislación adecuada a los objetivos centralizadores y la publicación de obras con la intención de justificar las grandes medidas - como el proceso a la nobleza no-adicta y la expulsión de los jesuitas - prueban claramente lo afirmado.

Finalmente, y por acabar, Portugal en la búsqueda de una ilustración que fortaleciera su foder, optó por una "ilustración católica", igual sucedió en España, rechazando las concepciones más avanzadas francesas. La frecuente censura de autores italianos y filósofos franceses - Montesquieu, Rousseau, Voltaire- parece confirmar lo dicho. Era la visión peninsular de que la llustración francesa podía traer el desorden y la anarquia. Por contra, la «ilustración católica» seguía proporcionando los elementos necesarios para el mantenimiento del poder absoluto.

Se han trazado unas líneas generales donde la principal idea era la del fortalecimiento del poder de la Monarquía.

Este fortalecimiento tuvo dos aspectos, en los que voy a detenerme: en el interior y ante el exterior. $Y$ todo ello fue obra del ya citado marqués de Pombal, en un principio don José Sebastián Carvalho e Melo.

Pero antes, considero obligado aludir a por qué pudo hacerlo. Por eso, me voy a referir al momento que considero de despegue, cuando este personaje se convierte en todopoderoso de modo que el rey José I deja el gobierno en sus manos. A partir de ahí, aceptará todo lo que le presente Pombal a la firma. Si no, es imposible explicar el proceso.

El momento forma parte de la historia general. Fue el terremoto que destruyó una gran parte de Lisboa el primero de noviembre de 1755. Se 
calcula que cerca de 40.000 personas perdieron la vida. Tesoros de particulares y públicos fueron absorbidos por el movimiento sísmico. La calamidad desató una oleada de crimenes de todo tipo; el desorden se generalizó de tal modo que se temia que muchos de los que habían escapado a la catástrofe fueran asesinados por el bandidismo.

El terremoto, escribe Teixeira, sirvió para hacer de Pombal el estadista de Portugal. Debido a las enérgicas providencias tomadas, al cabo de algún tiempo renació la confianza. Fue Pombal en ese tiempo criticado por todos los sectores de la sociedad pero rara vez en la historia se ofrece un ejemplo tan singular de gobernante y administrador. Los diplomáticos extranjeros acreditados en Lisboa relataron a sus Cortes la medidas tomadas por el ministro. Todo sirvió para preparar el fortalecimiento exterior del país. El pueblo se acabó por entusiasmar de las realizaciones. Durante el régimen pombalino fue solamente en ese instante en el que se sintió confortado por la admiración popular. Luego, las medidas que adoptó para fortalecer el poder serian criticadas por amplios sectores de la sociedad ${ }^{7}$.

Pombal escribió en sus Cartas lo que pensaba del terremoto: "Políticamente hablando, Portugal no perdió nada con esta "revolución". Se derrumbaron algunas piedras que estaban ya arruinadas y puestas unas sobre otras; la aniquilación de las mercadurias que casi todas pertenecian a extranjeros; el incendio de los muebles; y la pérdida de algunos vasallos ociosos que ni eran labradores, ni artistas, y que no hacian falta al sistema general. El fenómeno cayó sobre cosas materiales que, lejos de ser causa de la grandeza del Estado, eran por el contrario la fuente de su ruina» ${ }^{8}$.

Por ese tiempo, el anciano Pedro da Mota e Silva, que procedía del reinado antecedente, murió y Pombal asumió el puesto de Primer Ministro. Para que se ocupara de su antiguo cargo de secretario de Negocios Extranjeros fue Ilamado don Luis da Cuñha Manuel, que estaba en Londres.

Aún hoy, ciertos historiadores portugueses escriben que la actuación de Pombal no tuvo ningún mérito y que cualquiera en su puesto hubiera hecho 10 mismo. De todas formas, José I quedó fascinado por la laboriosidad de su ministro por atender sobre todo al triunfo del Bien Público.

Cierto es que la reconstrucción de Lisboa apenas impresionó a los portugueses, pero sí causó una profunda sensación en el espíritu de los

Telxelra Soares, A., O Marquês de Pombal. Brasilia 1961, págs. 131 y ss.

Telxelfa Soares, A., op. cit., pág. 137 
extranjeros. Estos observadores no dejaron de subrayar la rapidez de los trabajos y la belleza del gran cometido económico-social.

\section{EL FORTALECIMIENTO DEL PODER EN EL INTERIOR}

a) El proceso a la nobleza ${ }^{9}$

La forma de gobernar de Pombal, su política económica - con la creación de la Compañia de Comercio del Gran Pará y Marañón-, reunieron a descontentos. Si Pombal no se eliminaba a si mismo, debería ser eliminado por una conspiración ${ }^{10}$.

La oposición no organizada precisaba un jefe. Éste debía salir de la nobleza y por una razón: porque ésta le negaba el apoyo y sabía que muchos hidalgos, si no conspiraban abiertamente, por lo menos estaban organizando una campaña de descrédito.

Pero también la nobleza estaba dividida por la cuestión del Tratado de Madrid. La facción Ilamada "Viejo Portugal» entendía que los jesuitas debian cumplir escrupulosamente las cláusulas de aquél. Por consiguiente, se deberia tomar una actitud firme frente a la oposición provocada por la Compañía de Jesús. Otros cortesanos, más oportunistas, estaban aprovechando el conflicto no para defender los derechos de Portugal en tierras americanas sino para inutilizar al ministro que queria hacer prevalecer los intereses de la Corona.

De todas maneras, el renovador debia ser combatido por todos los medios porque acabando con antiguos privilegios, atajando la soberbia de los nobles y combatiendo la rutina, estaba modificando el vivir monótono de la sociedad entera. El hecho de haber enviado a la familia real a vivir en un pabellón de madera en Ajuda después del terremoto escandalizó a muchos, como también escandalizó el trazado de la monumental Plaza del Comercio donde mandó establecer «la bolsa de los negocios».

Por todo, no es de extrañar que muchos nobles reaccionasen contra el plebeyo dinámico. El P. Malagrida, de la Compañia de Jesús, subió al púlpito para fulminar al reformador que había traido a Lisboa el «castigo divino" del terremoto. Circularon impresos difamando al primer ministro

\footnotetext{
9 Véase apartado 1 del Apéndice documental.

10 Carreira, A., As Companhias pombalinas da navegaçao. Oporto 1969, págs. 20 y ss.
} 
y su familia, presentada como un conjunto de plebeyos litigantes y no escrupulosos. Hasta la reina Mariana Victoria parece dar aliento a los cortesanos enemigos de Pombal; además, sospechaba del proceder de su marido, José I, pensando que el primer ministro le protegía en sus desvíos sentimentales ${ }^{i 1}$.

Así estaban las cosas, cuando en 1756 el P. Malagrida publicó un opúsculo titulado Juicio de la verdadera causa del terremoto, editado con el consentimiento del Santo Oficio. En él se llamaba la atención del pueblo hacia los pecados cometidos por los hombres que habian traído el "Castigo divino". Con fama de santo, Malagrida pasó por un momento de popularidad, lo que no impidió que Pombal lo desterrase fuera de la Corte, a Setúbal. El antiguo misionero de Brasil habia hecho numerosos amigos en la Corte, por lo que éstos se irritaron ante la medida.

Éstos fueron los concretos precedentes de un movimiento de una parte de la nobleza no contra la Monarquía sino contra el ministro. Las intrigas subieron de tono en 1757 cuando Pombal reprimió con dureza un motín en Oporto con motivo de la creación de la Compañia de Viñas del Alto Duero.

A Pombal se le presentó la ocasión de castigar a esta nobleza el domingo 3 de septiembre de 1758 cuando José I, poco después de las 11 de la noche, se dirigia al Alto de Ajuda en un carruaje poco característico. Regresaba de hacer una visita a la marquesa de Távora (la joven) de quien sospechaba la reina. Tres caballeros embozados tiraron un tiro al cochero y fallaron. Más adelante, dos caballeros alcanzaron al carruaje y dispararon sus pistolas contra el monarca que quedó herido en el pecho, en el hombro y en el brazo derecho.

La versión oficial fue que cuando se encaminaba a los aposentos de la reina, José I cayó y se fracturó el brazo derecho ${ }^{12}$.

Sobre los hechos se montó una superestructura de fantasías, leyendas y suposiciones. A ello contribuyó el proceso cerrado que siguió y que impidió que la justicia esclareciese los diversos ángulos de la misteriosa trama, dejando hasta hoy en la sombra cosas importantes.

Hecho con rapidez el proceso, impidió a los reos que se defendiesen por lo que muchas cosas quedaron sin explicación alguna. Sea como fuere, el proceso fue el remate legal de una conspiración mal amañada. Con todo, la tentativa de regicidio sirvió ampliamente a los propósitos del primer ministro: abatir a la nobleza y liquidar a los jesuitas.

\footnotetext{
11 Azevedo, J. L. de, O Marquês de Pombal e a sua epoca, 2 ed. Lisboa 1990, pág. 129.

12 Teixeira Soares, A., op. cit., pág. 183.
} 
Dicho proceso, aún hoy, todavía es motivo de atención de los historiadores. Cada libro presenta tesis nuevas; quizás el más documentado sea el de Oliveira Santos titulado: El caso de los Távoras.

Desde el primer momento, el proceso adquirió un carácter eminentemente político. Fueron detenidos Aveiro, Atouguia, Távoras y mucha gente más; los establecimientos de los jesuitas fueron aislados de contactos con el exterior. Cuando empezó el proceso se supo enseguida que el castigo sería político y no jurídico; nada importaban las leyes cuando en medio estaba la integridad del monarca. Los mejores jueces se prestaron a la operación.

A lo largo del mes de diciembre fueron presas cerca de mil personas de toda condición: nobles y burgueses, plebeyos, criados y distribuidas por varias prisiones. Se utilizó la tortura para las confesiones: Aveiro confesó y se retractó.

Se quiso dar una apariencia de justicia y el Dr. Tavares de Siqueira fue nombrado defensor de los reos el día 4 de enero de 1759. Presentó la defensa en cuarenta y ocho horas, pero no impidió que el 13 estuvieran condenados y muertos en el patíbulo. En el transcurso de 30 dias se habian cumplido las sentencias.

Detrás de toda la conjura estaba el descontento de muchos sectores $y$, en especial, de la nobleza. Pombal, por tanto, tenía pretextos para, castigándola, someterla. Cuando el primer ministro convenció al monarca a que escribiera una carta a Clemente XIII el 5 de diciembre de 1767, en ella se decía que los jesuitas habian sido los instigadores de la conspiración de los nobles. Era una forma de reafirmar a los nobles adictos, para sustentarse en la posición social de la clase.

\section{b) La cuestión de los jesuitas ${ }^{13}$}

La máxima expresión de un Pombal atento a las miradas extranjeras fue la expulsión de los jesuitas.

Dicha cuestión se convirtió en «razón de Estado» para lograr un poder regio independiente de influencias externas. Para el ministro los jesuitas impedian el desarrollo de los planes de la Corona en América, dependian de Roma e influian en las distintas capas sociales de la metrópoli llegando a manejar, en definitiva, a los gobiernos.

\footnotetext{
${ }^{13}$ Véase docs. 2b y d del Apéndice.
} 
Por eso, fueron considerados como la imagen oficial de «lo rechazable» para el progreso del Estado.

Ellos habían sido la causa - escribe Cándido dos Santos- de todos los males del pais a partir de su instalación en tiempo de Juan II.

A partir de la intención primera - acabar con los jesuitas-, se organizó todo un clima propagandístico de rechazo, sustentado en los más variados ataques que iban desde la blasfemia, la magia y la idolatria hasta la impudicia, la lesa-majestad y el regicidio.

El mismo Compendio Histórico de la Universidad de Coimbra se dedicó a mostrar los estragos hechos en teologia, jurisprudencia civil y canónica y en la medicina. Fueron los jesuitas identificados con la escolástica y la reacción intelectual anti-jesuitica portuguesa se reflejó en una reacción anti-escolástica.

Pero el principio de la marcha hacia la expulsión fue algo económico y político, aunque el primer acto pudo ser la ejecución del citado P. Malagrida, acusado de regicidio. En su condena se incluyó a toda la Compañia de Jesús, cuyos teólogos venian justificando desde el siglo XVI el tiranicidio.

Pombal, favoreciendo la difusión de toda suerte de panfletos antiguos, intentó mostrar la permanencia de una política antiestatal de la Compañia de Jesús. De este modo, volvió a tomar el Memorial presentado al rey de España, Felipe IV, por fray Juan de San Diego Villalón en defensa de D. Bernardino de Cárdenas, obispo de Paraguay, contra los jesuitas e impreso en 1662; de él se hizo un extracto que venia a demostrar que los métodos de los misioneros no habían cambiado cien años después.

Los jesuitas habian instituido una república "comunista» donde la propiedad privada estaba reservada a la «nación». Cada individuo entregaba la totalidad del fruto de su trabajo y el «Estado» se encargaba de la subsistencia de cada uno.

Los cambios y el comercio no se hacian más que a un nivel comunitario y los productos eran almacenados y depués transportados por vía fluvial a Buenos Aires. Por otra parte, las tierras de las Siete Misiones eran fértiles y en 1759 producían trigo, algodón y mate cuyo comercio proporcionaba un milión de piastras anuales. Además, en las corrientes de agua habia pepitas de oro. Se calculaba que, en conjunto, el trabajo de los indios daba más de cinco millones de piastras al año.

El acusador indicaba: la Compañia se estaba apropiando de las riquezas, lo que implicaba el despojo de los pobres, y con ellas estaba tratando de organizar un Estado propio. Se decia que, de hecho, tenía «un negocio enorme que le producia en Europa enormes riquezas". Tal negocio 
había sido puesto de relieve por el cardenal Saldaña: en las misiones habia descubierto organizaciones bancarias (bancos públicos), libros de ventas, correspondencia, dinero, letras de cambio...

Lo cual había conducido al prelado a confiscar todos los valores y reservar a la Santa Sede el destino del producto de los efectos capturados ${ }^{14}$

Pero el problema de los jesuitas venia de lejos. Pombal con la reedición del Memorial citado había puesto de relieve un problema de la Corona de España que se continuaba con la de Portugal. Teixeira Soares, en su libro O Marques de Pombal, escribía que ya en el siglo xvII los jesuitas hubieron de enfrentarse a las expediciones sistemáticas de los paulistas - Sao Paulo- hacia el interior en busca de oro. Entraron a sangre y fuego en las de Acaraí poniendo en auténtico riesgo las del interior del Paraguay. Parece ser que los "descubridores" mataron a cerca de 300.000 indios entre 1614 y 1639. Teixeira para que no haya duda, indica que en este tiempo estaban unidas las coronas de Portugal y España y que a ésta, como dominadora, le tocaba poner fin a este genocidio ${ }^{15}$.

No cabe duda que en los territorios del Brasil meridional y el estuario del Plata era grande la actividad colonizadora de los jesuitas; además, habian establecido vinculaciones terrestres entre sus Reducciones y Buenos Aires, por un lado, y con el Alto Perú, por otro.

El 13 de enero de 1750 se firmó el Tratado de Madrid entre Portugal y España. En el artículo 1. ${ }^{\circ}$ se decía que se debían establecer unos límites fijos entre los dominios portugueses y españoles, y en el segundo que cada parte debía permanecer en los terrenos que poseía (para evitar lo que venía sucediendo desde hacia décadas con la incursiones de paulistas y españoles). También en dicho Tratado se establecia que Portugal cedería la controvertida colonia de Sacramento, junto a Montevideo, a cambio de los Siete Pueblos de las Misiones situados al norte. Se ponía, por tanto, fin a todas las pugnas que había acarreado el indeciso meridiano del Tratado de Tordesillas.

La cuestión de establecer las demarcaciones iba a traer muchos conflictos. Y precisamente por causa de las fronteras se produjo el encuentro armado entre los guaranies de las misiones jesuiticas y las tropas portuguesas; fue entonces cuando penetró en la conciencia nacional portuguesa la idea de la existencia de un verdadero «imperio" jesuístico, poseedor de inmensas tierras labradas, de aldeas trazadas geométrica-

\footnotetext{
${ }^{14}$ Véase doc. 2a del Apéndice.

15 Teixeira Soares, A., op. cit., págs. 105-106.
} 
mente, de milicias armadas... y que, posiblemente, ocultaban inmensas riquezas.

Está hoy fuera de duda que los jesuitas no vieron con buenos ojos pasar a la Corona portuguesa. Con España habian andado más a su aire y sus autoridades habian contemplado las misiones del Paraguay y Alto Uruguay con un criterio paternal, permitiéndolas vivir alejadas de la Corona.

Por eso, los jesuitas de Lisboa, que hasta ese momento se habian mantenido en segundo plano, tomaron como cosa suya presentar los inconvenientes del Tratado de Madrid y, al proceder asi, se convirtieron en los responsables del conflicto.

Pombal decidió intervenir. Los grandes del reino, atormentados por la idea de tener que tomar una decisión, no sabian qué hacer: si defender a los jesuitas, lo cual les convertia en enemigos de Pombal, o ponerse al lado de los que entendian que debía cumplirse el Tratado. La desorientación se veía agravada por las escaramuzas entre las tropas españolas y portuguesas contra los indios guaranies.

A Pombal lo que le preocupaba era que el Tratado de Madrid se viniera abajo por causa de la guerra guarani. Teixeira aporta más datos: algunos historiadores han afirmado que la Compañia de Jesús, a la vez que tenia un papel político en las cortes europeas, se interesaba por crear "un hombre nuevo» ante la fragilidad de los sistemas económicos y políticos de su tiempo. Sabian que el oro y los diamantes del Brasil podian ser fundamentales para el poder internacional de Portugal y conocian las intrigas de las cortes de París, Varsovia y Viena. Como admirables observadores políticos juzgaban que el mundo necesitaba de un espíritu renovador y no se engañaban. El problema era que en un momento de llustración todo el movimiento podía convertirse en una segunda Contrarreforma ${ }^{16}$.

Por ejemplo, los jesuitas fieles al iusnaturalismo, aparecian como defensores intransigentes de los derechos humanos, tal como más tarde serian aceptados en la Declaración de las Nacionales Unidas el 10 de diciembre de 1948; entre tanto los déspotas ilustrados exigian de sus súbditos obediencia absoluta y un Estado omnipotente.

Pero lo que unia a las cortes de Lisboa y Madrid era que los jesuitas podian crear en la selva paraguaya un Estado independiente. De hecho, no prestaron aquellos ninguna colaboración al Tratado de Madrid como

\footnotetext{
16 Teixeira Soares. A., Op. cit., págs. 127-128.
} 
pudieron comprobar los comisarios regios de ambos países en el momento de afrontar los límites. Pombal atacó a la Compañia porque se oponía a todos sus planes: disponia de poder político internacional y tenia un «imperio». Teixeira la compara a la Standard Oil que, como empresa, puede oponerse a los distintos gobiernos por separado. Por eso, Pombal sería el organizador de todo un movimiento internacional, después de haberlos expulsado, para alcanzar la extinción.

En Portugal, el ministro supo reunir adeptos entre la nobleza y la burguesía de las Compañias de comercio y de los negocios mostrando que los jesuitas habian organizado su propia Compañia comercial y que traficaban en un permanente contrabando.

Los incidentes que se produjeron en la selva guarani entre 1753 y 1756 le sirvieron para fortalecer esta versión. Las repetidas victorias de los indios en esos años, hasta que fueron derrotados ante las tropas portuguesas y españolas dotadas de artilleria, eran un indice de que los indios solamente podian estar mandados por jesuitas.

Azevedo afirmaba que en el carácter de la política de Pombal no había ninguna contradicción. Su divisa era el predominio ilimitado del rey, no reconociendo ningún otro superior dentro del país, ni a la misma Roma ni a la Compañía de Jesús. Por eso la expulsión de esta sociedad se debió, más que nada, a la imposibilidad de entenderse con ella y dividir la influencia de que gozaba, más que a odios mal entendidos ${ }^{17}$.

\section{EL FORTALECIMIENTO DEL PODER ANTE EL EXTERIOR}

El Tratado de Madrid de 1750 había dejado en el primer ministro muchas dudas sobre la actuación española. Por una parte, si los conflictos ocurridos en la transferencia de las misiones jesuiticas le habian dado la convicción de que la Compañia había estado detrás, por otra, la Corona española había dado la impresión de no colaborar con la portuguesa y de apoyar a los jesuitas.

Con todo ello se creó un mundo de sospechas; el juego castellano aparecia sinuoso y seguia siéndolo en 1757. En ese año parecia evidente, por las noticias recibidas de Brasil, que las autoridades de Buenos Aires y otros puntos de dominio español se mostraban poco inclinadas a cum-

1 Azebedo, J. L. de, Op. cit., págs. 233 y ss. 
plir el trazado de los límites. Lo que les importaba era haber conseguido la Colonia de Sacramento.

Esta desconfianza a cerca de los españoles sobre el cumplimiento del Tratado condujo a Pombal a tomar las riendas, en los años siguientes, de un Portugal internacional. Fue entonces cuando en el ministro surgió la idea de que el Tratado podría ser modificado, dependiendo siempre del acuerdo de las partes: ello significaba convencer a los españoles de que entregasen Sacramento. Llevó mucho tiempo diplomático, por un lado, atraer a españoles y, por otro, a los portugueses (que estaban satisfechos de haber logrado las misiones jesuíticas) hacia la necesidad de abolir el Tratado de 1750 y elaborar otro en su lugar ${ }^{18}$.

El resultado fue el Tratado de El Pardo, de 12 de febrero de 1761, por el que España, aunque parezca poco creible, entregaba la Colonia de Sacramento.

Los consejeros de Carlos III cayeron, aunque tarde, en la cuenta del error. Con el nuevo Tratado, Sacramento volvía a ser punto de discordia porque los portugueses habian vuelto a controlar la ribera norte del Plata para ejercer el contrabando con las mercancias españolas que viajaban por los rios Paraná y Uruguay y desembocaban en el rio de la Plata.

Sicológicamente, esto contribuyó para que se formase un ambiente poco agradable en las relaciones entre Lisboa y Madrid; pero de ellas salía Pombal fortificado.

El Pacto de Familia de 15 de agosto de 1761, que unió a los Borbones contra Inglaterra, fue el momento escogido por España para pedir a Portugal una definición. El primer movimiento de Pombal fue retirarse hacia una prudente neutralidad y el segundo solicitar apoyo de Inglaterra. Una de sus peticiones, la principal, era obtener la seguridad de que Inglaterra acudiría con ayuda militar en caso de guerra con España y Francia. Pombal se desmarcaba de toda política mediterránea e iniciaba la tradicional alianza inglesa.

El ministro inglés Pitt, haciendo suya la causa de Portugal, obtuvo en el Parlamento la aprobación de un subsidio de guerra de 1.000 .000 de libras y la organización de un cuerpo expedicionario que por lo menos deberia contar con 8.000 hombres. Era claro que Portugal no tenía ejército ni marina para desarrollar una política de poder.

En 1762 parecia evidente que Portugal mantenia con Inglaterra relaciones estrechas, aparte de los actos internacionales solemnes como

\footnotetext{
18 Véase docs. $3 a$ y b del Apéndice.
} 
eran los tratados. Es más, Portugal se ofreció a ser mediador en el conflicto de los Borbones con Inglaterra lo cual supuso un éxito diplomático de Pombal al saber aprovechar que ésta le necesitaba. Y la escuadra inglesa entraría en un puerto portugués para atacar a la francesa. La respuesta española fue que sus tropas entrarian en tierra portuguesa para impedir que los puertos fueran utilizados por las tropas británicas.

Volvió a adelantarse Pombal que el 18 de mayo de 1762 declaró la guerra a España antes que el marqués de Sarria iniciara la anunciada invasión.

La guerra fue calificada por los historiadores como una serie de operaciones de maniobras y contramaniobras absurdas. Las fuerzas españolas, muy superiores en número, pudieron haber conquistado Portugal, pero Sarría y el conde de Aranda, que llegó para sustituirle, se revelaron no buenos jefes. A la vez, de poco habian servido a Pombal los 8.000 soldados ingleses, en su mayoria irlandeses, dedicados a cometer todo tipo de excesos.

Mientras, Pedro de Cevallos atacó con 6.000 hombres la plaza de Sacramento que se rindió en octubre de 1762.

El 3 de noviembre se realizaron los preámbulos de la Paz en Fontainebleau entre Luis XV, Jorge III y Carlos III a los cuales logró añadirse el rey José I el 22 de ese mes. El Tratado definitivo de Paz se firmó en París el 10 de febrero de 1763.

Por dicho tratado, los portugueses volvieron a asegurarse Sacramento. Pero el resultado más importante de esta miniguerra fue la idea de organizar un verdadero ejército portugués al margen de apoyos externos. Se estableció un servicio de reclutamiento, se crearon cursos de artillería y fortificaciones; se importaron más de 1.000 piezas de artillería. Sin embargo, Portugal siguió sin tener generales porque la nobleza no estaba interesada en la carrera militar ${ }^{19}$.

Los planes de Carlos III seguían siendo separar Portugal de Inglaterra y conquistarlo. Choiseul aspiraba a crear un Brasil francés. Para ello, prometió a España la ayuda de 30 batallones para anexionar a Portugal en tanto Brasil pasaria al poder de Francia (asi lo señalaba Octavio Gil Munilla en su obra El Río de la Plata en la política internacional). La posición a estos planes fue Pombal; su diplomacia despistó a franceses (que querian Brasil para compensar la pérdida de Canadá) y a españoles. Luego

19 Teixeira Sonres, A., op. cit, pág. 194. 
sería atacado por sus mismos compatriotas de haber pactado con Inglaterra su participación en Brasil ${ }^{20}$.

De dónde venia la relación de Portugal con Inglaterra. Voy a hacer referencia al Tratado de Methuen, tratado comercial firmado por Inglaterra y Portugal el 27 de diciembre de 1703 (llamado así por su negociador John Methuen, embajador de la reina Ana en la corte portuguesa). Cierto es que apenas incide, en cuanto tal, en este trabajo, pero resulta el trasfondo para mostrar al estadista Pombal ante las crecientes pretensiones inglesas.

Dicho Tratado apenas constaba de más de tres artículos: por el primero, el rey de Portugal, y en nombre de sus sucesores, admitiria siempre los paños de lana británicos y otros derivados de la lana. Por el segundo, esta admisión era concedida bajo la condición de que S.M. Británica, y en nombre de sus sucesores, se obligaba a admitir los vinos producidos en Portugal con unos derechos de aduana inferiores en una tercera parte a lo que pagaban los vinos de Francia; en caso de que no fuese asi, el rey de Portugal prohibiría la entrada de paños ingleses. Y tercero, los plenipotenciarios se comprometían a que en el plazo de dos meses, los reyes firmarian el Tratado.

Tal Tratado fue criticado por los historiadores del siglo xIx pero sirvió para establecer unos lazos indispensables en el momento de entender las vinculaciones políticas de estos reinos. Mientras Adam Smith señaló que el Tratado había sido favorable a. Portugal, Federico List, en su tratado Economia politica, opinaba que Inglaterra había sido la gran beneficiada. En efecto, el Tratado había dado un golpe de muerte ai comercio de Holanda con Portugal y sus colonias y con las Indias Orientales, siendo sustituido por Inglaterra en un comercio que parecia ilimitado hasta el Extremo Oriente. De hecho, el Tratado fue la base para que, eliminados holandeses y alemanes de Oriente, estableciese inglaterra los sustentos de su Imperio. Y ello, evidentemente, a costa de su relación con Portugal.

Fuera lo que fuese, el caso es que Methuen significó la fama de un vino caracterizado, el Oporto; que Portugal fuera conocida por sus vinos y que se produjera un gran desarrollo comercial luso-inglés que sería la base para las permanentes relaciones politicas entre ambos países.

La misión de Pombal fue justamente establecer una igualdad práctica del Tratado. Ante la sensación de que los ingleses estaban sacando más provecho, y sin perder la alianza con Inglaterra, supo frenar las exigen-

20 Gil Munilla, O., El Rio de la Plata en la política internacional. Sevilla 1949, pág. 92. 
cias individuales de sus comerciantes. No dio importancia a las amenazas de los embajadores británicos cuando éstos intentaban defender las posiciones de sus comerciantes que estaban amparados por un Tratado anterior, el de 1654.

Este Tratado, arrancado por Cromwell a Portugal, señalaba que los ingleses establecidos en este país debian gozar de una serie de ventajas donde la principal era la de oponerse a las tarifas aduaneras que no les convinieran. Pombal respetó los compromisos políticos de Portugal pero no condescendió ante las peticiones de nuevos privilegios de los súbditos ingleses, lo que podia suponer para los portugueses un aumento de impuestos o un estar en inferiores condiciones comerciales. Incluso en 1773 amenazó con denunciar el Tratado de Mathuen, lo cual alarmó a los ingleses, pero era claro que únicamente queria Pombal frenar el posible poder práctico de los individuos comerciantes ingleses. Ello sirvió, si se mira bien, para frenar las demasiadas pretensiones inglesas ${ }^{21}$.

Portugal había aprovechado la alianza inglesa para mostrar su particular poder frente a España y Francia pero quedaba afirmar la independencia de Roma.

Esto resulta fundamental para entender el movimiento ilustrado de Portugal. Y con Roma los jesuitas.

El 3 de septiembre de 1759, un año después de la ejecución de los Távoras y de Aveiro, se dictó una ley ordenando que los jesuitas fuesen tenidos por desnaturalizados, proscritos y exterminados, siendo por siempre expulsados de Portugal. El cardenal Saldaña, patriarca de Lisboa, se prestó a demostrar en una pastoral que las altas autoridades del clero lusitano estaban a favor de la medida ${ }^{22}$.

Pombal, no contento con esto, y para provocar a Roma envió en septiembre a 133 jesuitas en un navio al puerto de Civita Vecchia, y en octubre, 122 jesuitas, procedentes de Brasil, también fueron enviados al puerto pontificio.

La ruptura de las relaciones diplomáticas entre Portugal y el Vaticano despertó el interés de toda Europa. Las corrientes anticlericales festejaron a Pombal como el primer estadista que había fortalecido el poder temporal y que habia liberado a su patria de la intromisión de Roma en los asuntos del Estado ${ }^{23}$.

\footnotetext{
Teixeira Soares, A., op. cit., pág. 205

${ }^{22}$ Véase doc. 2c del Apéndice.

23. Véase docs. 3o y d del Apéndice.
} 
A partir de 1764, y ante los deseos de Clemente XIII de restablecer las relaciones diplomáticas, Pombal empezó a poner como condición la extinción de los jesuitas. El papa defendia la existencia de la Compañía aunque hubiera sido expulsada de Portugal; por eso, cuando en 1765 llegó a Lisboa el Breve Animarum saluti en este sentido, Pombal lo declaró sin efecto, mandó entregar las copias existentes a las autoridades e impuso a los que las retuvieran la pena de confiscación de los bienes y otras penas establecidas por ley para los casos de "conspiración y ofensa a la regia majestad».

La muerte de Clemente XIII abrió la posibilidad de que el futuro papa acabara con los jesuitas. Pombal y Choiseul intervenieron para mediar el voto de los cardenales del cónclave, aquél propuso, además una serie de amenazas como la de que las potencias ocuparan el Estado romano e intimaran a los cardenales que no eligiesen a uno de ellos sino a un individuo extraño al Sacro Colegio, solución que no la impedian los cánones. No se llegó a eso, pero si a que el embajador portugués dijera que el cónclave estaba advertido de que el papa, de no secularizar la orden de los jesuitas, se arriesgaba a no ser reconocido por las potencias. El 19 de mayo de 1766 el cardenal Ganganelli ciñó la tiara con el nombre de Clemente XIV, mediante el pacto, declarado o tácito, de aniquilar a la Compañia que las coronas detestaban. Sin embargo, sosegada su ansia de poder, empezó a eludir la obligación y a ganar tiempo consciente de los riesgos que conllevaba la decisión.

Cuando por primera vez recibió a los representantes de los paises interesados en la extinción de los jesuitas, no dudó en prometerles que se produciría. Pero a Portugal, concretamente, le propuso que volviera a restablecer sus relaciones diplomáticas. Fue en diciembre de 1769 cuando se decidió restablecerlas; la baza del Vaticano era que el general de los jesuitas, P. Ricci, habia caido gravemente enfermo. Si moria, el papa prohibiría la elección de un nuevo Padre General, lo que suponia andar más de medio camino para el final. Sin embargo, Ricci curó.

Al mismo tiempo, el 3 de diciembre de 1769, habiendo salido a cazar José I fue atacado por un hombre sin lograr hacerle nada. Esto sirvió a Pombal para presentar a los jesuitas como instigadores y asi lo escribió a Roma.

En junio de 1770 llegó a Lisboa el nuevo nuncio y el 25 de agosto un decreto indicó que las relaciones con la corte pontificia se habian restablecido. José I, aliviado el peso de su conciencia, nombró a Carvalho de Melo marqués de Pombal ${ }^{24}$.

\footnotetext{
2. Azevedo, J. L. de, Op. cit., pág. 244.
} 
Los años siguientes fueron de insistencia por parte de las Cortes de Lisboa, Paris y Madrid en la extinción de los jesuitas. En enero de 1773 se acabó de hacer, por fin, la minuta de Bula de extinción de los jesuitas que fue llevada a las cortes europeas por medio del rey de España. A Lisboa llegó en marzo y fue aceptada. También la aceptaron Nápoles y Paris. Solamente Maria Teresa de Austria no la aceptó, inicialmente, porque no se le otorgaba la libre disposición de los bienes de la Compañia como a las naciones que la habian expulsado antes. Pero todo se solucionó con la concesión de dichos bienes.

La Bula de Clemente XIV fue comunicada a los jesuitas en la noche del 16 de agosto. La noticia de la supresión fue publicada en Lisboa el 7 de septiembre de 1773 .

Puede comprobarse cómo al expulsar a los jesuitas de Portugal, Pombal aprovechó para desterrar al Inquisidor General al convento de Buçaco y el negociador del Tratado de Madrid que estaba a favor de los jesuitas fue llevado al fuerte de la Junqueira. La Inquisición fue secularizada y transformada en una orden política y social como existía en algunas policias de otros países.

La expulsión de los jesuitas sirvió para que Pombal intentara una reforma de la enseñanza que estaba en misérrima situación. Dicha expulsión había traído, como indica Fernando de Azevedo, el cierre inmediato de 23 colegios y 17 residencias en Portugal, asi como el cierre de 25 residencias, 36 misiones y 17 colegios y seminarios en Brasil.

Tuvo que idear nuevos planteamientos. Si bien la fundación del Aula de Comercio fue el primer paso para instaurar los estudios de contabilidad, economía y comercio en Lisboa, la fundación del Tesoro general tenía el propósito de instaurar el método de contabilidad para las empresas públicas, intentando la creación de un cuerpo de funcionarios especializados. Pero Pombal se engañó al pensar que con leyes o decretos se podía elevar la cultura de un pueblo; además no contaba con medios para sustituir a los jesuitas.

Más importante que la modernización de la Universidad de Coimbra fue el decreto de noviembre de 1772 que establecía la enseñanza popular que debía ser dada en las escuelas públicas. Pombal no se quedó en el texto de la ley; pasó a crear escuelas que deberian completar un total de 479. A la vez, fundó un Colegio de Nobles, al modo que venía existiendo en España y quie lo habian regentado los jesuitas; y para mantener un equilibrio social y educacional fundó el Colegio de Mafra, destinado a la educación de los plebeyos. 
Considero que la interpretación de las cuestiones de la nobleza y de los jesuitas resultan indispensables para entender en profundidad el reinado de José I y su llustración.

\section{LA «VIRADEIRA» (EL VIRAJE, EL CAMBIO EN LA POLITICA)}

El 24 de febrero de 1777 falleció José I después de una larga enfermedad. Y una anécdota significativa que presagiaba el futuro: un día de esos meses de enfermedad, quiso Pombal entrar en la cámara del monarca para preguntar por su salud. El cardenal de Cunha, le detuvo, diciendo: "Vuestra Excelencia no tiene nada que hacer aquí.

Este cardenal, que era un Távora y había llegado al cardenalato por Pombal, representaba, sin duda, un ejemplo de la reacción que se iba a desencadenar contra el ministro.

En cumplimiento de la cláusula del testamento de su padre, la nueva reina María I mandó liberar a todos Ios presos; salieron más de 800 que Pombal había puesto en prisión.

Se desataron torrentes de calumnias contra el ministro y se imprimieron opúsculos y folletos atacándole y acusándole de mil negocios oscuros.

Había comenzado el viraje ${ }^{25}$.

En la sociedad, como suele suceder, predominó la pusilanimidad. Todo el mundo — nobles, burgueses y plebeyos-intentó acomodarse a la nueva forma de pensar y sentir. Tales eran las protestas contra Pombal, que daba la impresión de que el primer ministro durante 27 años no había hecho nada.

Pero había más: era preciso que el ministro pagara todos los excesos cometidos en el reinado anterior que habían llevado la firma del monarca. Lo más importante era acabar de un golpe con todas las reformas y volver a lo que era Portugal en 1750 - un gran reino de la frivolidad, de gastos con el oro del Brasil y de privilegios dados por el soberano-; para llegar a eso estaban las intrigas de nobles hidalgos y eclesiásticos que fueron aprovechando las ganas de la reina de contentar a todos.

Pombal dimitió el 4 de marzo de 1777. Los nuevos ministros de la reina eran invención de Pombal: él los había promocionado y ascendido.

25 Belrao, C., Dona Maria l. Lisboa 1934, pág. 11. 
Una vez en el poder, participaron en la campaña contra Pombal para aprovechar la nueva onda.

La primera acción diplomática de la nueva era se constituyó en un modelo de cómo acabar con lo realizado antes. Si José I había fallecido en febrero, el primero de octubre de ese año de 1777 firmó Portugal en Madrid el Tratado de San IIdefonso (ya con el conde de Floridablanca) por el cual Portugal perdía la colonia de Sacramento, las misiones del Alto Uruguay y el territorio fronterizo del sur de Brasil. La nueva política portuguesa queria la paz con España a cualquier precio.

Al cesar a Pombal de su cargo, la reina en su carta incluía una precisión: se reservaba arreglar los posibles desvios de la Hacienda real. Con lo cual abría la puerta para que el ex-ministro fuese procesado.

Éste se defendió redactando una memoria dura en la que hacía la defensa de su gobierno. Todos los nobles aspiraban a participar en el gran proceso que, en realidad, sería también el análisis del gobierno de un rey dotado de poder absoluto. Entonces Pombal escribió su defensa formal, la Deducción cronológica, que causó gran impresión. A raíz de ella, los nobles más prudentes empezaron a pensar que sería arriesgado revolver el pasado que podría ir contra ellos e, incluso, contra la casa real.

Hay que pensar que en el reinado de María I seguian las mismas prácticas de absolutismo regio que habian orientado el de su padre. Hay que decir que tampoco sa convocaron Cortes en este reinado. Como es sabido, las Cortes habian sido reunidas por última vez el 8 de enero de 1698 y no se volvieron a convocar hasta el reinado de Miguel I en 1828, esto era, 130 años después. Si el gobierno de Maria I no se caracterizó por la energía y clarividencia del reinado anterior, ofreció algo peor: degeneró en un absolutismo mandarinesco que además, contaba con ministros irresolutos. Fue en este reinado, por ejemplo, cuando se publicó el decreto, muy a la inglesa, de cerrar todos los talleres y fábricas de Brasil.

Cierto es que la reina vivió un gran drama de conciencia. En cuanto a la cuestión de los jesuitas escribe Caetano Beirao: «Para con los jesuitas individualmente, todas las atenciones y benevolencias; para con la Compañia no, por las múltiples razones de conciencia y de Estado (...) Nos parece, en suma que esta fue la posición inteligente mantenida por la reina de cara al problema» ${ }^{26}$.

Por otra parte, sabia la reina que atacar a Pombal era, en definitiva atacar a su padre José I. ¿Cómo establecer una frontera delimitadora en-

\footnotetext{
26 Beirao, C., op. cit., pág. 22.
} 
tre el poder real y la autoridad del primer ministro?; habia sido José I el que había firmado las sentencias contra la nobleza o la expulsión de los jesuitas o habia roto las relaciones con Roma. Para la concepción de gobierno de la época, estaba fuera de duda que el monarca hacia y deshacía sin ninguna limitación señalada por la ley, y al margen de concepciones nuevas ilustradas.

El 9 de octubre de 1779, dos jueces anunciaron al ex-primer ministro que se le iba abrir un proceso; daba la impresión que los magistrados estaban empeñados en revolver todo el pasado de la administración del anterior reinado.

Dicho proceso estaba todavía en su fase de interrogatorio cuando Pombal falleció el 8 de mayo de 1782, a la edad de 83 años.

El reinado de José I habia supuesto un intento de colocar a portugal a tono con el orden ilustrado internacional. Ahora Portugal volvía a cerrarse como la España de Carlos IV. 


\section{APÉNDICE DOCUMENTAL*}

\section{Indice de documentos}

1. Sometimiento de la nobleza.

a) Del proceso y sentencias por regicidio (enero, 1759).

b) Noticia sobre la ejecución de los acusados de regicidio (enero, 1759).

c) Declaración del rey sobre los culpables del atentado (enero, 1759).

2. Expulsión de los jesuitas.

a) Disposición del Cardenal Saldaña como Visitador y Reformador Apostólico de la Compañía de Jesús (mayo, 1758).

b) Adición a la eruditisima Apologia... Defensa de los jesuitas (enero, 1759).

c) Expulsión de los jesuitas de Portugal (septiembre-octubre, 1759).

d) Observaciones sobre la conducta que ha tenido el ministro de Portugal... Defensa de los jesuitas.

3. Relaciones internacionales. La ruptura con Roma.

a) Representación enviada por el Padre Pedro Lozano de la Compañia de Jesús al rey de España... (marzo, 1751).

b) Portugal, España, Inglaterra y los jesuitas. El Tratado de Madrid (recopilación de noticias, 1755-1759).

c) Ruptura de las relaciones diplomáticas entre Portugal y Roma (junio, 1760).

d) Ruptura de las relaciones diplomáticas entre Portugal y Roma (decretos y resumen del proceso. 1760).

\section{SOMETIMIENTO DE LA NOBLEZA}

a) Del proceso y sentencias por regicidio

En el Palacio de Nuestra señora de Ajuda (12 de enero de 1759).

(...) Muéstrase más en confirmación de lo referido que entrando la dicha maŕquesa (de Tavora) en la referida confederación, así ella como los dichos religiosos

\footnotetext{
* Fuente: Archivo de la Provincia de Toledo de la Compañía de Jesús. Alcalá de Henares (Madrid).
} 
jesuitas trataron de persuadir a todas las personas de su conocimiento y amistad que Gabriel Malagrida, religioso de la misma religión, era hombre penitente y santo haciendo la dicha marquesa, como hizo, ejercicios espirituales guiada por la dirección de dicho religioso, mostrando que seguía enteramente sus dictámenes y consejos, y causando con estas observaciones de creencia en el dicho Gabriel Malagrida y de sujección a su espíritu daños tan grandes, como fueron; 1. Hacer esta rea a su casa una cotidiana asamblea de improperios y calumnias para concitar aversión y odio contra la R. Persona de Su Majestad y su felicísimo gobierno. 2. Ser la conversación ordinaria de la misma casa una continua plática de traiciones y maquinaciones contra la R. Persona del mismo Señor, asentándose en ellas que seria muy útil que el mismo Señor dejase de vivir; y haciéndose sobre este abominable principio en casa de la misma marquesa muchos de los ajustes y confederaciones para cometerse y mantener el sacrilegio insulto de la noche del 3 de septiembre del año próximo pasado. 3. Confederarse la misma marquesa por aquella conformidad de sentimientos detestables con el Duque de Aveiro hallándose con él en los otros ajustes y maquinaciones que se hicieron en casa del mismo duque para privar al Rey de su preciosisima y gloriosisima vida a fin de que asi cesase el gobierno feliz del mismo Señor. 4. Confederarse también la dicha marquesa con el referido Gabriel Malagrida, su continuo y absoluto director, con los jesuitas Juan de Matos, Juan Alexandre y otros. 5. Constituirse la misma marquesa una de las tres principales cabezas de esta bárbara y horrible conjuración para extenderla procurando con su autoridad y artificio por los medios arriba declarados y otros meter en la misma conjuración todas las personas que le fue posible engañar. 6. En fin, juntarse la misma rea inmediatamente con los pérfidos y sacrilegos ejecutores del execrable insulto de esta noche del 3 de septiembre de año próximo pasado contribuyendo con 16 monedas para parte del premio que se dio a los infames y detestables monstruos que en aquella infructuosisima noche dispararon los sacrilegos tiros que hicieron los enormisimos estragos que todos lloramos.

Muéstrase más, que prosiguiendo la misma marquesa aquel abominable plan y teniéndose abrogada la despótica dirección de todas las acciones del marqués Francisco de Asis de Tavora, su marido, de sus hijos e hijas, yerno, cuñados y otras personas; abusando infamente de aquella autoridad con que a todos dirigia para pervertirlos, fue la que arrebatada por un espíritu de soberbia luciferina de mandar y de la hedrópica codicia de adquirir; juntándose a estos fines con el duque de Aveiro y con los dichos religiosos jesuitas, como queda mostrado, concurrió impia inhumanamente en la misma confederación y en el horrible insulto del 3 de septiembre del año próximo pasado los dichos su marido, hijos, yerno, cuñados y amigos como se verá luego, sirviéndose para esta infernal obra no sólo de la opinión que fingía tener de la pública santidad del sobre dicho Gabriel Malagrida, mas también de las cartas que él frecuentemente escribía para persuadir a todos los ejercicios a Setúbal con el Malagrida.

Muéstrase más que en consecuencia de aquellos diabólicos antecedentes, el primero de los secuaces que miserablemente se precipitó en la infamia de dicha conjuración fue el marqués Francisco de Asis de Tavora siendo arrastrado a caerse en el mismo precipicio por las persuasiones de dicha marquesa, su mujer; del 
duque de Aveiro, su cuñado; y de los religiosos jesuitas, de suerte que llega a hacer su casa una infame oficina de confederaciones, traiciones y maquinaciones contra la alta reputación y preciosisima vida de Su Majestad, hallándose también con los mismos abominables fines en las perniciosas conversaciones y confederaciones que se tuvieron, e hicieron en la casa del duque de Aveiro para mudar el gobierno de Su Majestad y de privar al mismo Señor de su preciosísima vida: de suerte que llegó a llevar el mismo duque 12 monedas o cincuenta y siete mil y seiscientos reis que le cupieron por su parte del vilísimo premio que se dio a los dos asesinos, adelante declarados, antes de que cometiesen el insulto de 3 de septiembre del año próximo pasado, de suerte que luego al tiempo del mismo insulto por la pública voz y fama y por la opinión y ciencia cierta de los familiares de ambas casas y de los compañeros del sobredicho inscrito, fue reputado y declarado el dicho marqués de Asís por uno de los correos de aquel exacrando delito. Probándose, sobre todo, específicamente que para ello concurrió y que estuvo en una de las emboscadas que infamemente se armaron en aquella funestísima noche de 3 de septiembre del año próximo pasado, para que si el Rey N.S. escapase de unas, fuese a caerse en las otras. De suerte que después del referido delito, en la misma noche de él, fue visto cuando se recogia o se retiraba de las dichas emboscadas, en una tierra que está por detrás del jardín del dicho duque de Aveiro, hablando con los otros correos sobre el mismo delito que todos acaban de auxiliar; y de suerte, también, que se halló en una junta de parierites o conciliábulo, que la mañana próxima siguiente al insulto del 3 de septiembre, se tuvo en casa del mismo duque de Aveiro, culpando a los asesinos porque no había ejercitado el golpe con todo su pernicionisimo efecto, y jactándose otros de que no lo hubieran así ejecutado si el Rey N.S. hubiera pasado por las emboscadas en donde ellos se hallaban apostados para esperarie.(...)

(Archivo de la Provincia de Toledo de la Compañia de Jesús. Varios. M-31, fols. $86-88$ )

\section{b) Noticia sobre la ejecución de los acusados de regicidio}

SEMANARIO DE LISBOA

(16 enero, 1759)

«El día 10 de este mes murió la madre del duque de Aveiro, monja de la Concepción, sin saber nada de la prisión de sus hijos. Este mismo dia trajeron por la noche a la marquesa de Tavora, madre, que estaba en las Grilas juntamente con una criada y la pusieron en la casa de los Leones. El mismo día 10, se echó el Rey sobre las casas del duque de Aveiro, que estaban en la ciudad. Este mismo dia se le señaló a la condesa del Atoguia 25 doblones de mesada y 110 reales al día para todos los criados. El 11 se embarcó un batallón de Infantería para Salvatierra. La noche de este dia trajeron con soldados a la Casa de los Leones a ocho padres de la Compañía de Jesús, entre ellos al corfesor que fue de este Rey, al del Infante D. Pedro, al de la Princesa y Infantes, al que fue de D. Juan V, y al Procurador del Gran Pará. Este mismo dia entraron en Tribunal Pleno todos 
los principales ministros de los consejos, y estuvieron hasta las siete del día siguiente (que es el 12).

Este día se les leyó la sentencia, y se les dio a los reos no sé qué horas para su descargo: a las nueve y media hubo un temblor de tierra bastantemente sensible; por la tarde se dio a Su Majestad a los reos que estaban en la cárcel de Belén. Al anochecer entraron en la casa de los Leones cuatro Padres Gilitos, cuatro de las Escuelas Pias, Ilamados de Riafoles, y cuatro Carmelitas para auxiliar a los reos que estaban en dicha casa. A las ocho de la noche bajó un regimiento de la ciudad.

A las nueve y media trajeron el cadalso hecho en diferentes piezas escoltado de soldados, que le pusieron en la Plaza de Belén, cerca del mar.

A las dos de la noche se les dió el viático a los reos, y esta misma noche bajaron otros dos regimientos de la ciudad, se formaron en tres columnas haciendo frente los dos de la caballería.

A las seis y media sacaron de la casa de los Leones (que está frente del patíbulo o cadalso) en una silla de manos a la marquesa de Tavora, precedida de los ministros de Justicia a caballo, y al subir al cadalso pidió confesión, y se estuvo en ella una hora de reloj, y después se volvió a reconciliar, y sentándose en una palomilla o asiento raso, la ató el verdugo las manos, cintura y guarda pies, diciendo Jesús saltó la cabeza fuera, la cual cubierta y el cuerpo con un paño negro, se siguió la segunda justicia, que fue a su hijo D. José María, de edad de 21 años, ayudante de su padre por lo militar, precedido de la misma comitiva, y con mucho valor pidió al Rey y al pueblo perdón, se reconcilió en el cadalso, y puesto en una aspa echado, al mismo tiempo que le iba dando garrote con una cuerda un verdugo, el otro le iba quebrando brazos y piernas con una maza de hierro. Así mismo murió, y le pusieron en una rueda de ocho que habia, cubierto lo mismo que su madre.

El tercero el conde de Atoguia, sentado las manos en cruz en una aspa, dado garrote lo mismo que al otro, y después de muerto lo quebraron los huesos con la misma maza.

Cuarto. El Marqués de Tavora, mozo, hermano mayor de José María, la misma muerte que al de Atoguia.

Quinto. Un criado de Tavora, mecánico, a éste le sacaron de la cárcel descalzo, y le dieron la misma muerte que al antecedente y en el mismo cadalso.

Sexto. Un criado del duque de Aveiro, mecánico, llevó la misma muerte sacándole de dicha cárcel.

Séptimo. Un cabo de escuadra del regimiento de Alcántara, y le sacaron de la casa de los Leones, ejecutando el mismo castigo que con los antecedentes

Octavo. El Marqués de Tavora, padre, subió con ánimo al cadalso, y mirando a todos se confesó alli mismo de rodillas, y la caballeria le volvió la espalda, ceremonia por ser su General y traidor, le dieron la muerte tendido en un aspa, y con una maza de hierro, que con trabajo la levantaba el verdugo, y a éste le tapó la cara con un lienzo, como a todos, y después con la maza le dió el primer 
golpe en los hombros, y después en el pecho y en los demás miembros nasta que murió, siendo seis o siete golpes los que le dieron.

Noveno. El duque de Aveiro salió con un vestido encarnado sin peluquín, con un Cristo en las manos, y le dieron la misma muerte que al de Tavora, a excepción de que al otro empezaron a darle los golpes por arriba y a éste por las canillas de los pies.

Un criado del mismo duque, quemado vivo, junto con la estatua de otro compañero que no se sabe de él, y ofrecen al que de noticia o le traiga muerto o vivo 10.000 cruzados.

Todos los reos se pusieron en las ruedas dichas, y juntamente con el quemado al que descubrieron todos los cuerpos de dichos reos, y todos juntos se quemaron y por la tarde echaron las cenizas a la mar.

La duquesa de Aveiro, dicen está setenciada lo mismo que su hermana la de Tavora, pero no se ha ejecutado por estar embarazada.

El domingo catorce cantaron el Tedeum por Su Majestad Fidelísima los maestros plateros; este día fue a Salvatierra un escuadrón de caballería. Así mismo todos los caballos del Rey para este sitio, que todas son prevenciones para ir Su Majestad el viernes.

El dia quince salió Su Majestad Fidelísima a dar gracias a Nuestra Señora de las necesidades pues es el primer día que sale de Palacio. Este mismo día 15 se ha sabido cómo han cogido al que se escapó y le quemaron la estatua.

Estas son las noticias presentes.»

(Extracto de las noticias del "Semanario de Lisboa».

Archivo de la Provincia de Toledo de la Compañia de Jesús. Varios, M-75, doc. 2).

c) Declaración del rey sobre los culpables del atentado

(18 de enero de 1759)

Yo el Rey: Hago saber a los que este albalá de Ley vieren, que siéndome presente la sentencia que en 12 del corriente mes de enero pronunció la Junta de Infidencia para el castigo de los reos del bárbaro y execrado delito que en la noche del 3 de septiembre del año próximo precedente se cometió contra mi Real Persona, y que entre las penas que en la misma sentencia se impusieron a los sobredichos reos se comprende la efectiva reversión, y actual incorporación en mi Real Corona, de todos los bienes vinculados que por ellos eran tenidos y poseidos en la parte en que hubiesen sido constituidos de bienes de la misma Corona que de ella habréis ensalido por cualquiera modo, manera o título que fuese, como los fueron, por ejemplo, los bienes declarados en las donaciones de la Casa de Aveiro y los demás bienes de la misma naturaleza que eran poseidos o administrados de los sobredichos reos, y que lo mismo se observase por lo perteneciente a los Patronatos de cualquier naturaleza que fuesen. Soy servido aprobar, ratificar y confirmar las dichas decisiones no en forma común sino en forma 
eficaz y especifica motu propio cierta ciencia, poderio real pleno y supremo para que las referidas decisiones en todo y por todo se cumplan y guarden como en ella se contiene sin embargo de la ordenanza del libro quinto, título 6 paragrafo 15 de las clásulas de las donaciones e instituciones exuberantes e irritantes que sean y de cualesquiera disposiciones de derecho u opiniones que sean en contrario, las cuales todas y cada una de ellas las doy aqui por expresas como si de ellas se hubiese hecho especial mención para derogarlas como las derogo quitándolas toda la fuerza y vigor para que como revocadas y nulas no puedan producir jamás efecto alguno en juicio ni fuera de él.

Establezco que no sólo observe asi en el caso precedente declarado por la dicha sentencia, no obstante haber sido la pena impuesta después del delito, y sin embargo de las disposiciones contrarias mas también que lo mismo se practique para el tiempo futuro en el castigo de todos los crimenes de Lesa Majestad. de primer orden.

Y mando a Manuel de Moya, maestre de campo de mis ejércitos y guarda mayor de la Torre del Tumbo, que en ella haga casar, romper y destrozar todas las donaciones y títulos que en ella se hallaren escritos siendo pertenecientes a bienes de la Corona que hayan sido poseidos o administrados por los reos que fueron condenados por aquel execrable delito para que de los mismos títulos como casados y anulados no se puedan extraer copias algunas, y que asi se haya de practicar de aqui en adelante en los casos que se cometiere crimen de Lesa Majestad de primer grado.

Los traslados de las referidas donaciones y titulos que ya se hallaren extraidos en manos de personas particulares, ordeno que no puedan tener fe ni crédito alguno en juicio ni fuera de él y que no se puedan alegar, y menos atender, mas antes por el contrario luego que fueren apareciendo los magistrados a quienes se presentaron o los que de ellos tuviere noticia, los remitan o denuncien al Procurador de mi Corona para enviarlos a la Torre del Tumbo donde serán despedazados y rotos como títulos nulos y reprobados; lo mismo establezco que observe por lo respectivo a los plazos o Patronatos así como ahora ha sido juzgado, para que se practique por lo futuro en la forma sobredicha como la providencia dada en beneficio de los directos señorios por la ordinación del Libro 5, tit. 1, parágrafo 1. Y solamente por lo perteneciente a los otros mayorazgos fundados de bienes patrimoniales de los instructores que los fundaron, permito que se observe y quede observado lo que se haya determinado por la otra ordenanza del libro 5, título 6, parágrafo 15 .

Este se cumplirá como en é! se contiene con las cláusulas derogatorias arriba referidas y con las demás que doy aqui por expresas a fin de que en todo y por todo sea firme y eficaz. Por lo que mando al Doctor Manuel Gómez de Carballo, de mi consejo desembargador del paso y Chanciller mayor del reino, que lo haga publicar y pasar por la Chancilleria y remitir los ejemplares de él a todas las cabezas de partido. $Y$ ordeno al Presidente del desembargo del paso (regidor de la casa de la Suplicación), Gobernador de la Casa del Puerto, veedores de mi Real Hacienda, Presidentes de la Mesa de Conciencia y Ordenes, Consejo ultramarino, y a los ministros que sirven sus cargos desembargadores de las dichas 
relaciones y a los demás ministros y oficiales de justicia y personas de todos mis reinos y señorios, que asi lo ejecuten y observen sin duda ni embarazo alguno registrándose éste en los lugares donde se acostumbre a registrar semejantes leyes. Y mando se lleve el original a la Torre del Tumbo. Dado en este mi Real Palacio de Nuestra Señora de Ayuda a los 17 de enero de 1759. Rey. Sebastián, José de Carvalho y Melo.

Albalá o Pragmática de Ley por la que V.M. es servido aprobar, ratificar y confirmar la condenación de la sentencia en la Junta de Inconfidencia se pronunció contra los reos del bárbaro y sacrílego desacato que en la noche del 3 de septiembre del año próximo pasado se cometió contra la Real Persona de V.M., por lo que pertenece a la reversión e incorporación de los vínculos constituídos de los bienes que hubiesen sido de la Corona, y de los Patronatos de cualquiera naturaleza que sean; estableciendo que lo mismo se practique para el tiempo futuro en aquellos casos en que se cometiere crimen de Lesa Majestad de Primera Cabeza. Todo en la forma arriba declarado. Para V. Majestad verlo, Manuel Gómez de Carballo.

(Archivo de la Provincia de Toledo de la Compañía de Jesús. Varios, M-31, fols. 79-81).

\section{EXPULSIÓN DE LOS JESUITAS}

a) Disposición del Cardenal Saldaña como Visitador y reformador Apostólico de la Compañia de Jesús (1758)

A todos los que la presente vieren, o de ella tuvieren noticia, salud y paz en Nuestro Señor Jesucristo. Desde la fundación de la Iglesia Católica fue prohibido a todas las personas dedicadas al sacerdocio manchar su santo ministerio, mezclándose en los negocios seculares..

Habiendo sido tan manifiesto y sensible el escándalo que han dado en estos reinos y sus dominios los eclesiásticos ilicitos y negociantes, que hasta la misma ley de la Patria en auxilio y socorro de los Sagrados Cánones y Constituciones Apostólicas, dio la providencia de mandar secuestrar los magistrados seculares las mercadurías con que negociaban semejantes personas dedicadas a la iglesia para remitirlas a los jueces ordinarios con los autos hechos de ellas.

Y por cuanto somos informados con certeza, no sin gravísimo dolor de nuestro corazón, de que en los Colegios, Noviciados, Casas de la religión de la Compañía de Jesús en estos reinos y sus dominios a Nos cometidos para reformarlos y reducirlos a la debida observancia de sus obligaciones en todo, y en lo que cupiese en nuestras débiles fuerzas, se hallan no obstante, algunos religiosos tan olvidados de las sobredichas disposiciones divinas y Constituciones Apostólicas, y tan obstinadamente endurecidos en la transgresión de ellas, que sin temor de Dios, y sin vergüenza del mundo, en grave perjuicio de sus almas y general es- 
cándalo de los fieles: unos imitando a los Nummularios y negociantes que Cristo Nuestro Señor arrojó fuera del templo, reprendidos y azotados, están dentro de las propias casas de sus habitaciones religiosas, y como tales dedicadas a Dios, no sólo aceptando y expidiendo letras de dinero a cambio, como se practica en los bancos y casas de comercio, mas también vendiendo mercadurias traidas de la Asia, de la América y África para negociar en ellas; como si los dichos colegios, casas, noviciados y residencias y demás lugares fuesen almacenes de negocios, y las habitaciones Lonjas de mercaderes. Otros imitando también a los negociantes eclesiásticos de quienes los Sagrados Cánones y los Santos Padres mandaron huir como de la peste, cuando pasan de pobres a hacerse ricos, y de humildes a arrogantes, con los caudales que de prohibido comercio acumulan. Se tiene averiguado tener establecidos almacenes situados en los lugares marítimos de las ciudades de estos reinos y sus dominios, donde haya mejor vecindad a los pueblos, donde hay más frecuente comercio, vendiendo en los mismos almacenes géneros y haciendas al pueblo, como cualquiera de los mercaderes públicos, habitantes en los referidos lugares; y otros en fin (obrando sin ejemplo) en los dominios ultramarinos de estos reinos llegan a más deplorable corrupción de mandar buscar drogas en los cercados, para venderlas después; demandar salar carnes y peces para el mismo fin; demandar, también, salar y acumular cueros para negociar y hasta tener dentro las propias casas de sus residencias tiendas de géneros mojados o de haciendas comestibles, azogues, y otras oficinas puerquisimas, aun respecto de los mismos seculares de la clase de los plebeyos.

En consideración a todo lo referido por autoridad Apostólica a Nos concedida, siguiendo las mismas disposiciones divinas y canónicas Bulas pontificias y más especialmente la comisión que tenemos de Su Santidad: Mandamos en virtud de santa obediencia y baja de excomunión mayor «ipso facto", y las demás que se hallan expresadas en todas y en cada una de las Bulas arriba trasladadas, a los RR. Provinciales, Vice-Provinciales, Prepósitos, rectores y demás Prelados locales, y sus respectivos súbditos de la Compañía de Jesús en estos reinos y dominios; a todos los sobredichos en general y a cada uno de ellos en particular, que en la misma hora, en que ésta les fuere presentada, o sea manuscrita o impresa firmada por Nos, y refrendada por nuestro llustrisimo y reverendísimo secretario, y adjunto, y sellada con el sello grande de nuestras armas, leyéndola en plena comunidad convocada a son de campana, y haciéndola registrar en los libros de las respectivas casas, donde fuere dirigida; luego en su cumplimiento hagan cesar las sobredichas transgresiones y escándalos con todas y todos los que fuesen a ellas, o a ellos semejantes, sin que para palearlas, negociando de cualquier modo, aunque sea por una vez solamente, aunque algunos de los dichos pretextos sean, o por necesidad de sus respectivas iglesias o de negociar por interpósitas personas, o el de interpretar las referidas Constituciones Apostólicas en sentido diverso del que se contiene en su literal disposición, o de que necesitan de tiempo para concluir los negocios, en que se hallan actualmente implicados porque todos los referidos efugios están ya reprobados por las mismas Constituciones Apostólicas arriba referidas, para que surtan su debido efecto, y se les dé por Nos su plenaria ejecución por lo que pertenece a los dichos RR. Prelados y religiosos de la Compañía de Jesús, nuestros súbditos. 
A los cuales declaramos por las presentes letras, que todas y cada una de las sobredichas negociaciones, aunque sean lícitas a los seculares, son torpes e ilicitas respecto de los eclesiásticos porque la prohibición que éstos tienen para comerciar, comprende todas las negociaciones, que no sean la compra de las cosas necesarias y la venta de las superfluas. Extendiéndose aun dicha prohibición hasta las mismas negociaciones que provienen de las obras de las propias manos, cuando no son muy decentes a los religiosos; siendo aún mucho más ilicitas y más torpes las dichas negociaciones respecto de los religiosos misioneros que, como tales, están ligados por las disposiciones divinas y Constituciones Apostólicas con los más fuertes vínculos; y por eso estrechan también indispensablemente nuestra conciencia en esta omisión de que nos hallamos encargados, para no permitirlos la menor relajación por dichos respetos.

Por todo lo cual, mandamos otrosi en virtud de santa obediencia y bajo de la misma conminación, de declararlos incursos en todas y en cada una de las penas establecidas por las mismas Constituciones Apostólicas arriba sustanciadas, que en el térmirio perentorio y preciso de los tres primeros dias, que continúa y repartidamente se siguen en la forma de Derecho Canónico a la intimación que de ésta les fuese hecha, hagan y vengan a declarar ante Nos en esta ciudad de Lisboa y fuera de ella ante nuestros competentes Subdelegados, las negociaciones de cambio de dinero, de transporte de mercadurias, o sean secas dellas que sirven al uso y ornato de las personas, y de las casas, o sean mojadas de las que sirven para el alimento y sustento de la vida humana, en que al presente se hallan interesados; los caudales, mercadurias que, en razón de las mismas negociaciones, tienen actualmente en ser; y las acciones que por los titulos de ellas pertenecen a cada una de las respectivas casas religiosas asi en estos reinos y sus dominios, como fuera de ellos; exhibiendo al mismo tiempo en nuestra presencia, y en la de nuestros dichos Subdelegados todos los libros, cuadernos y papeles pertenecientes a las mismas negociaciones que se hallasen en la jurisdicción, y en el poder de todos y cada uno de los sobredichos prelados, y de todos y de cada uno de sus respectivos súbditos; y declarando dónde paran aquellos sobre dichos libros, cuadernos y papeles que no se hallasen en el poder o jurisdicción de los sobre dichos Prelados o sus súbditos, y la razón que hubo para pasar a aquellas manos, donde se hallasen, aquellos que no fuese posible exhibirlos, para que plenamente instruidos de todo, podamos dar sobre las dichas negociaciones caudales y efectos de ellas provenientes, las providencias del servicio de Dios que fuesen más conformes a las determinaciones de la Santa Sede Apostólica y a! bien espiritual de la reforma a Nos cometida Por Su Santidad.

Dada en Nuestra residencia de Ziqueyar a 15 de mayo de 1758.

(Trancripción en castellano. Archivo de la Prov. de Toledo de la Compañía de Jesús. Varios, c-317, 4). 
b) Adición a la eruditisima Apologia cuyo título es: "Defensa por la fama póstuma de José Mascareñas, antes Duque de Aveiro, y demás llamados reos de Lesa Majestad en la sentencia pronunciada en Lisboa, el 12 de enero de 1759"

(defensa de los jesuitas)

Comenzó el año 1755, siempre memorable para Portugal y muy especialmente para Lisboa. Salió Carvallo con un plan de Compañia de Comercio para el Gran Pará y Marañón; hicieron los Mercantes llamados de la Mesa del Bien Común, representación a S.M. como en semejantes casos solian, de que dicha Compañia conforme el Reglamento que en el plan se daba, era de notorio detrimento para el público y de gravisimos daños para la Real Hacienda, como se evidenciaba en el memorial que presentaban. Carvallo, que nombrándose socio de dicha Compañía con el contingente de 200.000 ducados, aunque en realidad (como yo lo sé con toda certidumbre) no había contribuido ni con dos maravedís, esperaba todavía de los administradores de dicho negocio el interés que correspondiera a doscientos mil ducados, si, en verdad, con ellos hubiera concurrido. Empleó su valimiento y maña en sostener el proyecto con el empeño que pedia tanta utilidad suya. No hallando qué responder a las objeciones de los del bien común (tal era su fuerza) caminó, por el atajo, en que jamás tropezó hombre de conciencia tan escrupulosa como Carvallo; interpretó tan siniestramente el memorial de los Mercantes que, entendidas al revés sus expresiones de celo, les hizo cargo de que amenazaban sediciones etc. $Y$ en esta inteligencia fueron arrestados, tratandoles en la carcel con la estrechez de reos de Lesa Majestad.

Así ellos como sus deudos presentaron a S.M. Fidelisima por manos de Moreira (jesuita) sus peticiones, en que probando la injusticia que les hacian sus Ministros, imploraban la conciencia que pedía el caso. Nada obtuvo Moreira. Vuelvo a decir al lector, advierta el Despotismo que en los negocios de Corte se habia abrogado el jesuita, cuya pérdida por la expulsión de Palacio era prudente fundamento para que el Duque (Aveiro) no medianamente instruido en las máximas de Corte le juzgase enojado contra el fidelisimo y le hallase dispuesto para el insulto más atroz. Desterró Carvallo como más le plugo a los celosos mercantes y oficiales de Mesa que tenían parte en la impugnación de la Compañia del Gran Pará y Marañón. El tiempo les mostró que les hizo Mons. Carvallo no pequeña gracia, pues los pudiera ahorcar como lo hizo a los de la ciudad del Porto que en octubre del 57 condenó por reos de Lesa Majestad dando su jurisprudencia Carvallica a una borrachera el nombre de rebelión contra las leyes reales para que se mantuviese su compañía de vinos. Llámele su Compañía porque además de ser de ella el principal socio (como de todas) (mire el lector cuánto brilla en este primer ministro el desinterés, condición no sólo apreciable, pero indispensablemente necesaria para hacerse a todos justicia), le pagan los administradores tres ducados por cada tinaja de vino que por cuenta de la Compañia, se vende; de suerte que extendiéndose ella ya el término que llaman tierra de Feyra, percibe de donativo S.E. muy carvalla 60.000 ducados al año; pero los muchos que por complacer a Carvallo, temiendo su enojo si no lo hiciesen arriesgaron dine. ros en dicha sociedad, no sé hayan hasta ahora recibido algún interés; y lo peor 
es que los más prudentes ni reembolsar el fondo esperan ya. Sí de la Compañia del Gran Pará saca, en efecto, Carvallo el lucro que se prometió cuando más de un año anduvo ideándolo (así lo dijo la Sra. Dña. Maria Magdalena, hermana suya monja dominicana, del convento de la Anunciada de Lisboa, que sobrado tiempo ha vivido en casas de dicho Carvallo para atestiguarlo por no se le ocultar en sus afanes). O si las ventajas percibidas del Pará corren parejas con las de Porio, yo no sabré discernirio ni afirmarlo: diré sí me parece vaticinio aquel dicho del capitán Juan Silva que llegó al Marañón en marzo de 1755 con las órdenes para el establecimiento de la consabida Compañia poniendo éste en orden y armados en el convez de la embarcación sus soldados no permitió subiesen a ella los que de la playa venían a bordo, preguntado qué traía de carga respondió: Pólvora, balas, armas y grillos; y no hay duda que todo esto ha sido para aquel estado la famosa Compañía de Carvallo, y no poco de ello ha participado el Reino. Los géneros venidos por cuenta de dicha Compañía (que sóla ella los puede conducir) se venden hoy día al mayor precio, y los del Marañón son obligados, por no se les pudriesen, a venderlos al arbitrio de los socios de Carvallo, pero aun este inicuo, porque violento, desfalco en las compras y exceso en las ventas, no basta para sacar de lo poco que al presente viene de aquel estado el mismo lucro que cuando por no faltar en los indios que iban a las cosechas de los frutos, se conducían muy copiosos para el abasto de Portugal, y en gran cantidad para paises extranjeros.

Así mismo para que dicha compañia registrando el año pasado de 1759 sus libros de cuentas no se hallase con la deuda de 200.000 ducados, no bastó la usurpación de las canoas de los misioneros jesuitas en el año de 1757 cuando volvian cargadas del sertón, bajo de pretexto que dichos Padres no tenian ya a su arribo el gobierno temporal de los indios, como sino hubiera ley del Sr. Rey D. Juan $V$ en que expresamente hablando de los jesuitas dice que ellos no deben estar de peor condición que los otros sus vasallos, para que no se puedan aprovechar de aquellos frutos del pais que son «primi capientis», cuales eran los que cargaban las canoas de los misioneros y son sus rentas en aquel país; y además de dicha Ley y lo que en el asunto se manda en el regimiento de las misiones, no las enviaron los jesuitas para susodicha condición, sin facultad del obispo del Pará, que entonces lo gobernaba en ausencias del hermano de Carvallo, y el trabajo de los indios se lo habian ya pagado de antemano los jesuitas. De suerte, que no hay apariencia que excuse aquella sorpresa de verdadero hurto y rapiña. Para instrucción del curioso lector añado que aunque la carga de la flora del Marañón del año 1759 conforme su lista fue ocasión de risa a los que saben cuál solia ella ser antes de la nueva Compañia de Carvallo, el oro, que en dicho papelazo hacia más bulto, no era de su consecha. Desgraciados aquellos que trayéndolo del Mato Grosso con todos despachos se hallaron burlados en el Pará, donde como buena presa se lo sacaron, ni consiguió su restitución uno de los dueños que vinieron a Lisboa a solicitarla. Para decirlo en menos palabras, el Marañón (a juicio de los más bien instruidos según el pie en que allà se hallan las cosas) está en todo y por todo en la más lamantable ruina, y si no es absolutamente irremediable, son sin duda necesarios muchos años para repararlo (...). 
(Archivo de la Provincia de Toledo de la Compañia de Jesús. Varios, C-317, 18).

c) Expulsión de los jesuitas de Portugal

CARTA DEL REY JOSE ! AL CARDENAL. PATRIARCA DE LISBOA

(dia 3 de septiembre, 1759)

Francisco, Cardenal Patriarca de Lisboa.

Siendo el Rey mi señor servido expeler de todos sus reinos y dominios, por justos y necesarios motivos, los clérigos regulares de la Compañía de Jesús, nos participó es noticia por carta signada de su propio puño, cuyo tenor es el siguiente (...).

Cuando las provincias de estos reinos se hallaron más colmadas de los beneficios y honras, que tiene recibidas, y estuvieron copiosamente recibiendo de la magnificencia de los señores reyes, mis gloriosisimos predecesores, y de la mi Real Benignidad; se mancomunaron como absolutos árbitros de la dirección de mis vasallos, se hicieron directores generales de sus conciencias, y más ciegos se mostraron contra mi real trono y de cualesquier otros religiosos; empezaron luego a maquinar las clandestinas y violentas usurpaciones que tienen hechas en el estado del Norte y Sur del Brasil, no tan solamente en mis dominios, más también en la libertad, honra y hacienda de los habitantes de ellos. Cuando contemplaron que las dichas usurpaciones no podian dejar de ser descubiertas al tiempo de la ejecución del Tratado de los límites, pasaron inmediatamente (para impedir lo contrario y mantener de este modo en las mismas usurpaciones) a animar contra mi real Persona y gobierno a algunos Principes soberanos, con quienes Yo siempre había conservado la más cordial inteligencia y la más fina y sincera amistad. Cuando estos reciprocos afectos desconcertaron aquel tan inicuo proyecto de discordia exterior, pasaron al punto estos mismos Regulares en mis propios dominios uitramarinos la dura y elevosa guerra, que tanto ha escandalizado y horrorizado a todo el Universo.

Cuando que habian sido en gran parte derrotados los ejércitos y los tumultos de indios engañados, que toda la América tenian sublevada con revelión y supersticiosas abominaciones, subsiguientemente pasaron a suscitar dentro de mi propio Reino sediciones intestinas, en las que mezclaron y armaron contra mí a mis mismos vasallos, dando disposiciones para inficcionarlos. Hicieron que se precipitasen en el horroroso absurdo que intentaron ejecutar contra mi real Persona la noche del 3 de septiembre del año próximo pasado, con la infidelidad e infamia que jamás se imaginaron de los portugueses. Finalmente, habiendo errado aquel abominable golpe disparado contra mi misma Real vida, la que la divina Providencia preservó con tantos y decisivos milagros, mas no imaginando ni discurriendo que ejecutar para saciar su cruel y bárbara ceguedad, pasaron e intentaron contra mi alta reputación a cara descubierta maquinando e infundiendo para esto a los jesuitas de Roma y a sus mayores amigos, y haciéndolo esparcir por 
toda Italia, a fin de hacer odioso mi real nombre. Los infames agregados de tan disformes y manifiestas falsedades en toda Europa han encendido una universal indignación contra estos mismos perniciosos Regulares, habiendo visto tan claramente en presencia de la justicia fallar tan libre y sacrílegamente, viendo tan descubierta su calumnia que no pudieran buscar la menor verosimilitud que disfrazase sus falsedades, blasfemando contra las verdades más auténticamente públicas y notorias; viendo violado tan bárbaramente, y sin reparo alguno ni medida, el respeto debido a las potencias soberanas por unos hombres que tuvieron y deben tener por Instituto y única forma, la santa humildad.

$Y$ viendo, finalmente, asi mismo excedidos por los jesuitas de Roma todos los excrandos atentados de los jesuitas portugueses. Pues que habiendo éstos conspirado contra mis Estados y contra mi Real vida, pasaron aquellos a tirar y herir tan disformemente contra mi Real reputación, en que pende el alma y vigor de toda la monarquía, que la misma divina Providencia me entregó para que la conservase indemne e ilesa en la autoridad que es inseparable de lo Soberano.

Por estas indispensables tengo determinado que los Sobredichos Regulares inficcionados, deplorablemente enajenados de su Santo Instituto y manifiestamente separados de él por tantos, tan abominables y tan inveterados vicios para la observancia de su regla, como notorios rebeldes, traidores y adversarios, que tanto han sido y son actualmente de mi Real Persona y estados, y de la paz pública y bien común de mis fieles vasallos; sean pronta y efectivamente exterminados, desnaturalizados, proscritos y expulsos de todos mis reinos y dominios, para que nunca jamás puedan entrar en ellos. Ordenando que bajo la pena de muerte natural e irremisible ninguna persona de cualquier estado, o condición que sea: les dé entrada en mis reinos y dominios ni menos tenga con ninguno de ellos correspondencia alguna o cumunicación de palabra, ni por escrito, aunque acontezca que a estos mis reinos y dominios vengan en diversos hábitos y aunque hayan pasado a cualquier otra religión, a menos que para ello no hayan obtenido primero inmediata y especial licencia mía, con la que se habia admitido y asi practicado. Lo que me ha parecido participaros. No tan solamente para que como Reformador y superior delegado de los sobredichos Regulares, según el Breve Apostólico de Vuestra Comisión, fijéis y publiquéis esta inteligencia y religiosísima observancia, que tengo practicada con la Santa Sede Apostólica en todo aquello que podia aludir al aumento de! respeto a su santa autoridad; más también para que como Prelado Diocesano podáis exhortar a vuestros súbditos en todo el estado eclesiástico a fin de que como buenos y leales vasallos no dejen de dar ejemplo de fidelidad y celo a los seglares, para la mejor y más exacta observancia de esta mi sobre dicha real o indispensablemente necesaria determinación y providencia y que con ella tengo dado antes de ahora (por lo correspondiente a lo temporal) asi para el sosiego público de todos mis reinos y dominios como para la tranquilidad común de mis leales vasallos. Porque por aquella deplorable conjuración de los dichos Regulares (con diferencia de todas las órdenes religiosas, cuyo común se conserva siempre en su loable y ejemplar observancia) se hizo un cuerpo que constituye el gobierno del común de la sobre dicha Compañía; siendo muy regular que en ella pueda haber algunos particulares individuos de aquellos que todavía no habian sido admitidos a la solemne profesión, los cuales 
se hallan inocentes por no tener ni concurrir todavia en ellos aquellas necesarias pruebas, para poder confiarles los horribles secretos de tan abominables conjuraciones e infames delitos, en virtud de esta consideración, no obstante los comunes dirigidos a la guerra y represa universalmente recibida y cotidianamente observada en perjuicio de todas ias naciones escandalizadas, en las que viven más religiosamente. Os digo lo segundo, que todos los individuos de la sobre dicha Compañia, sin excepción de alguno de ellos, se hallan sujetos a los mismos procedimientos por los insultos cometidos contra mi y contra mis fieles vasalios por su pervertido gobierno. Con todo, reflexionando mi benignisima Clemencia la grande aflicción que han padecido todos aquellos de ios referidos particulares, que habiendo ignorado las maquinaciones de superiores se vieron alistados como partes de aquel cuerpo inficcionado y corrompido. He tenido por bien de permitir que todos aquellos de los dichos particulares que todavía no han solemnemente profesado y que a vos hubieren recurrido para que les relajéis los votos simple y que presentaren dimisorias vuestras, puedan estar seguros en nuestros reinos y dominios como vasallos de ellos no teniendo otra culpa personal probada que los inhabilite. Ylustrisimo y Reverendísimo en Cristo Padre, Cardenal Patriarca de Lisboa, Reformador General de la Compañia de Jesús en estos reinos y sus dominios, mi hermano muy amado

Nuestro Señor tenga a vuestra persona en su santa guarda. Escrita en el Palacio de Nuestra Señora de la Ayuda, a los tres de septiembre de 1759. El Rey.

PASTORAL DEL CARDENAL PATRIARCA DE LISBOA

(día 5 de octubre, 1759)

Y como por nuestro Pastoral oficio estamos precisados con indispensable óbligación a dirigir a nuestros súbditos por todos los caminos más seguros para su salvación, les advertimos que por derecho natural, por derecho divino y por el derecho de las gentes, deben amar a su Soberano, respetar sus Decretos y obedecer todas sus Leyes.

Bien nos muestra esta infalible verdad el apóstol San Pablo, que siendo escogido para predicador de las verdades católicas, eficazmente persuadía a sus oyentes que aquellos que resistian las leyes de su Soberano ofendian gravemente a la Majestad divina; porque el poder de los monarcas dimanaba o era dado por Dios y que todo cuanto ellos determinaban venia ordenado por su Altisima Providencia, y que aquellos que erradamente no obedecian sus leyes concurrian infelizmente en su eterna condenación.

El Espiritu Santo manda a los Reyes que tengan presente y entiendan por qué su poder les es concedido por el Señor. Por la divina Autoridad gobiernan los Soberanos: son legitimos legisladores, mandan y determinan lo que es justo. Por todos modos nos persuade el Altisimo cuánto debe ser respetado el poder y autoridad de los Soberanos, proponiéndonos como ejemplo más eficaz y más poderoso la obediencia de los mismos irracionales; porque sin este orden, se haria imposible la conservación de sus distintas especies. 
Mandó Dios a Samuel que oyese a su pueblo en todo aquello que le dijese: porque no era Samuel el ofendido sino es que lo era el mismo Dios, a quien se encaminan todas las ofensas.

No solamente como católicos (como en tantos lugares nos 10 persuaden los Santos Padres) están los súbditos obligados a respetar y obedecer a sus Monarcas; mas también por la utilidad pública; porque será imposible la paz y sosiego de las Monarquías sin la providencia y autoridad de sus Reyes.

Además de que esperamos que todos nuestros súbditos (teniendo presente la incomparable felicidad de ser vasallos de un monarca, el más piadoso y justo) deban sentir, y aun escandalizarse, que la Sociedad de los jesuitas se halle aparlada de su Santo Instituto y desquiciada tanto de las necesarias obligaciones de humanidad conspirasen no tan solamente contra la sagrada Persona del monarca y contra sus dominios, mas también, con escandalosa obstinación, pretendieron ofender a su real reputación y respeto. Por tanto, exhortamos a todos nuestros súbditos seculares, y mandamos a todos los eclesiásticos, que no tengan comunicación alguna con los dichos religiosos desnaturalizados, ni de palabra ni por escrito para que no se perturbe otra vez la paz y sosiego público que todos debemos procurar efectivamente, no solamente como verdaderos católicos sino tambièn como fieles y vasallos.

$Y$ ya que la comisión que nos hizo nuestro Santisimo Padre Benedicto XIV, de gloriosa memoria, fue en el efecto tan infeliz y tan inútil, que en lugar de producir en estos religiosos una verdadera humildad y una justa observancia de su Santo Instituto, han descaecido más en sus precisas y católicas obligaciones, rogamos a todos nuestros súbditos nos ayuden a pedir a Dios quiera darles aquellas Luces necesarias a estos infelices, para que conociendo sus indisculpables errores, busquen otra vez el verdadero camino, por donde siempre los guie su Santo Patriarca con sus admirables y perfectas obras a las más seguras y católicas doctrinas. Y para que ésta venga a noticia de todos, mandamos sea publicada en las Iglesias de nuestro Patriarcazgo y fijada en los lugares acostumbrados.

Dada en el Palacio de nuestra residencia. Bajo nuestro signo y sello. Junqueira, cinco de octubre de 1759.

Firmado, Cardenal Patriarca. Por mandado de su Eminencia, Cristóbal de la Rocha Cardozo.

(Traducción al castellano anónima. Archivo de la Prov. de Toledo de la Compañía de Jesús. Varios, M-75, doc. 3).

d) Observaciones sobre la conducta que ha tenido el Ministro de Portugal con los negocios de los jesuitas

(defensa de los jesuitas)

(...) En el caso presente D. Sebastián Carvalho, primer ministro y primer privado del rey de Portugal, representa a S.M. que los jesuitas le han usurpado una 
gran parte de sus dominios ultramarinos, que han sublevado contra él a sus vasallos; que le han declarado la guerra en la América, y la sostienen con indecible pertinacia. Se representa que dentro de su misma Corte han armado la diestra de algunos asesinos contra su sagrada persona, que de ellos tuvo el origen el execrable insulto de 3 de septiembre. Le representa que los jesuitas tienen por máxima asesinar a los príncipes, urdir conjuraciones, alborotar la paz pública de los estados, y que a esto se encaminan todas las experiencias que hacen antes de recibir alguno a la profesión solemne. Se representa, por último, que todos los jesuitas del mundo en común han esparcido negras y atroces calumnias contra él para infamarlo. Todas estas cosas le representa como ciertas y probadas. Se muestra los documentos de ellas que tienen la apariencia de legitimos y sinceros. Se hace ver libros estampados en Roma que lo contestan con la mayor aseveración y, acaso, se da también a entender que no habiéndose procedido a la prohibición de estos libelos, como se hace en todos los libelos infamatorios, vienen a estar, en cierto modo, como canonizados del sumo Pontífice.

Estas mismas cosas hace que se las confirmen personas nada sospechosas. Nadie le dice palabra en contrario, porque el Ministro no permite el acceso al Trono, sino aquellos que hablan piensan lo que él quiere. Y en un Príncipe naturalmente bueno, cuanto incapaz de cometer fraude, otro tanto ajeno de temerla; oyendo decirse y conformándose tales cosas de tales personas, pudo menos de creerlas?, y si las cree podrá dejar de castigarlas?

Sean en buena hora los jesuitas inocentes cuanto se quiera, si el Rey los cree reos de tan ernormes delitos. El tiene razón, que le sobra para tratarlos con el último rigor. Serán injustas en sí mismas sus resoluciones, más él no por eso dejará de ser justo, y por tal deberá tenerle todo el mundo. Finalmente, en él no puede presumirse pasión, o transporte de cólera contra los jesuitas, pues ha amado y protegido y favorecido siempre a estos religiosos sobre todas las demás órdenes regulares.

Más no puede decirse otro tanto del Ministro. Su antigua notoria aversión a los jesuitas y generalmente a todos los que podian oponerse a sus proyectos, su misma indole, su carácter, desobliga de buscar razones para defender su justicia en esta causa. Por otra parte, él ha manejado el negocio por sí mismo; y asi por lo que a él le toca, no puede haber lugar a engaño, que le sirva de excusa, y demás de esto la serie de hechos, que hemos visto en la conducta de este negocio, funda una justa sospecha de que él se ha dejado conducir del espiritu de pasión, más que del de la justicia, contentándonos con que juzguen los hombres de bien, y desapasionados, solamente iremos recorriendo lo generalmente la serie de su conducta, y advertiremos algunas cosas dignas de observación. El Público ha de ser el Juez. Una de dos deberá concluir necesariamente: o que todos los jesuitas son malvados más allá de lo que se puede pensar, o que debe ser muy injusto el Señor Carvalho que los culpa de tantas maldades. En una disyuntiva de esta naturaleza probablemente el Público se inclinará antes a favorecer a una numerosa comunidad de hombres religiosos que a un hombre de mundo. Pero de nuestra parte le rogamos que quiera desnudarse de semejantes preo- 
cupaciones. No se juzgue de modo alguno por favor y esté sola y estrechamente a las reglas de lo justo, y a la evidencia de los hechos. (...)

(Archivo de la Prov. de Toledo de la Compañia de Jesús. Varios, M-31, fols. 127-128).

\section{RELACIONES INTERNACIONALES. EL TRATADO DE MADRID Y LA RUPTURA CON ROMA}

a) Representación enviada por el Padre Pedro Lozano, de la Compañia de Jesús, al Rey de España desde Córdoba del Tucumán el 21 de marzo de 1751 sobre los inconvenientes del Tratado de Madrid

Es innegable, Señor, que de subsistir los portugueses en la dicha Colonia (de Sacramento) se siguen a la Corona de Castilla, y a todo el comercio del Perú, tan grandes y tan notorios perjuicios que a cualquier costo se deben evitar; pero el medio de este trueque, que se ha tomado, no es para evitar tales perjuicios, sino que éstos quedan en pie, y quizá se aumentarán y se seguirán otros grandisimos inconvenientes, que serán irreparables. El entregar a la Corona de Castilla sola la Colonia de Sacramento es un pretexto especioso para deslumbrar a los que lejos de estos Países consideran las cosas, pero no puede deslumbrar a los que de cerca las vemos con nuestros ojos: por qué esta entrega de la Colonia evitará el mal que recibe la Corona de Castilla y el comercio del Perú, si con ella se entregarán también otras poblaciones que subrepticiamente han ido fundando los portugueses en el Río Grande, en San Antonio, en el río San Francisco, en la isla de Santa Catalina, que todas están situadas en tierras muy adentro de la demarcación de Castilla; si todas se restituyeran a Castilla, y Castilla las despoblara, por estar lejos de los confines de los portugueses, mediando unos desiertos entre ellos y los castellanos, entonces sí que tuviera Castilla verdadero y sólido interés de que se le entregara la Colonia del Sacramento; pero por más que ésta se entregue a Castilla, si quedan las otras sobredichas poblaciones portuguesas (como quedan con mejor derecho con el nuevo ajuste, si se llega a ejecutar) entonces quedan tan dueños los portugueses para introducir sus géneros como hasta aqui, y para extraer y extraviar la plata de Potosí, y de otros minerales, y nada, nada totalmente se habrá remediado con la entrega de sola la Colonia de Sacramento, porque el Rio Grande está en tal positura, que hay desde el camino carretero hasta la villa de Montevideo, y a la Colonia que en ese caso será de Castilla, y de alli pueden pasar por tierra o por río a Santa Fe, como ahora lo hacen.

(Cit. en Teixelra Soares, A., O Marqués de Pombal. Brasilia 1961, pág. 126).

\section{b) Portugal, España, Inglaterra y los jesuitas. El Tratado de Madrid}

Recopilación de noticias desde el año 1755 hasta el de 1759 tanto en orden a los sucesos del Paraguay cuanto a lo que mira a la persecución de los padres de 
la Compañia en Portugal. Enviadas por un ministro de Estado y esparcidas en Nápoles por otro ministro, las que remitió a España a un confidente suyo.

Hallándose la nación inglesa empeñada en 112 millones de libras esterlinas y temiendo que la de España uniese sus fuerzas con las de Francia, tanto para recobrar la plaza de Gibraltar en Europa como también las que tenía en la América, pensó aprovecharse del tiempo en el cual la España deliberaba sobre el partido que debía tomar en las actuales circunstancias en que se hallaba constituída la Europa para prevenir los daños que resultarían así a su comercio como a sus colonias en América si acaso la España se declaraba contra la Inglaterra.

Los medios que se proponian los ingleses eran de tal naturaleza que solamente se hallarian éstos en estado de sostener la guerra con vigor si sus bastas ideas se proporcionaban a lo que tenian mediado de antemano. Y hallando que en sus principios pintaban bien, se proponian poner un pie estable en la América Meridional, lo que sucediendo asi inmediatamente les sobrarian medios para pagar las deudas de la nación en general y en particular, y se prometian de este modo asentar un comercio estable y floreciente y mucho más opulento que antes.

Pero como no podia la inglaterra obrar en este negocio directamente y al descubierto, pensó, para promover este proyecto, servirse del ministerio de Portugal, valiéndose de éste y de las circunstancias que actualmente estaban de antemano movidas y tenian bien meditadas para ponerlas en ejecución según los sucesos fuesen acaeciendo. Pensaron dar un tinte a su proyecto que pareciese en la apariencia favorable al Rey Católico y, en la realidad, conveniente a sus ideas. Veamos, pues, los medios que se tomaron.

Es de suponer que a la embocadura del Río de la Plata tienen los portugueses una Colonia llamada del Sacramento que es el refugio y nido de cuantos contrabandos se hacen en aquella parte de la América Meridional, con perjuicio notable de los intereses del rey de España, lo que produce continuos litigios entre España y Portugal. En el año 1750 empeñaron los ingleses al rey de Portugal para el fin de proponer a su Majestad Católica que, para quitar todos los motivos de discordia y perpetuar la unión y amistad entre las dos Coronas, su Majestad Fidelisima cedería al rey de España la mencionada Colonia del Sacramento, con tal que su Majestad Católica, cediese, por su parte, a Portugal cualesquiera colonia confinante al Brasil y otro terreno en sus inmediaciones equivalente a lo que cedia Portugal, ponderando, al mismo tiempo, las ventajas que se le seguían a España en virtud de lo mucho que sacrificaba Portugal en esta común concordia con la cesión de la rica y opulenta colonia del Sacramento; la que supieron ponderar tanto que de ella se llenó de papeletas toda España con el engaño que Portugal queria hacer creer al aducir la poca inteligencia de aquel terreno.

Pero antes de hacer a! Rey Carólico la propuesta, se procuró por medio de los ministros de Portugal en Madrid, y sobre todo por la reina, disponer el Consejo del rey para que se aceptase el proyecto sin más examen.

Dispuestas asi las cosas a satisfacción del Rey de Portugal, se vino al Tratado, en el cual exagerando los portugueses las grandes ventajas que abandonaban, cediendo dicha colonia del Sacramento, pedian en recompensa siete colonias si- 
tuadas en la orilla del rio de la Plata, a la parte septentrional de él y confinantes al Brasil, pertenecientes al gobierno espiritual y temporal de Buenos Aires, disminuyéndolas tanto que decian en sus informes que eran todas ellas unos lugares de indios forajidos, siendo tan al contrario que eran siete lugares tan bien plantados como puedan hallar en España, y tan numerosos que el que menos constaba de doscientos vecinos, y su terreno tan bien cultivado como cualquiera otro en Europa, y de gente tan dócil y leal a su rey como otro ninguno, y que en varias ocasiones han sabido desempeñar su fidelidad contra los enemigos de su Rey.

A más de esto pretendian los señores portugueses la ciudad de Tuy con todo su obispado que contiene aquella parte de Galicia con que confina Portugal con España, logrando de este modo cerrar aquella porción de mar que corre desde el Ferrol hasta el cabo de San Vicente, que tendria de costa más de 200 leguas cogiéndole a España en lo que se pretendia los puertos de Bayona, Vigo y Pontevedra, sin otras villas y lugares considerables.

El Rey de España, queriendo informarse si el cambio o cesión era proporcionado a las ventajas que se prometian en la posesión de la Colonia del Sacramento, situado a la orilla del río de la Plata y frente de Buenos Aires, le eran convenientes como en los informes se decia remitió al Consejo la propuesta y éste sin determinar por entonces cosa, condescendió y convino en que se escribiese al gobernador de Montevideo, vecino a la Colonia del Sacramento, y que se esperase su informe como se hizo. Pero al mismo tiempo que salió de acá la Orden para el gobernador, le fueron escritas de Carvajal letras conminatorias para que informase favorablemente según lo que se pretendia con la promesa de elevarle a mayor fortuna, con lo que prevaleciendo en él más el propio interés que el de su rey y su patria, hizo el informe el gobernador a gusto de la reina, principal interesada en esta materia y del partido que favorecia la parte de Portugal.

En consecuencia de esto fue enviado allá el marqués de Valdelirios con ingenieros para establecer los confines y ejecutar el cambio de la colonia del Sacramento con los Siete lugares dichos, enviando también al gobernador de Buenos Aires el Orden que se traía de España, al que habiéndoselo hecho saber, y la importancia de la comisión, quedó sorprendido de semejante atentado, y quiso hacer una directa oposición al tratado de la comisión, juzgando que este cambio que se intentaba hacer, era engañoso y contrario a los intereses del rey de España e indecorosa a la Monarquía, pero viendo las Ordenes de España hubo de ceder.

El gobernador de Montevideo, comisionado para esta contrata, tuvo habilidad para ganar al Provincial de los jesuitas y hacerle entrar en el abono del informe que hacia para Madrid, y éste, poco práctico en estas cosas por hacer poco tiempo que estaba en estos paises, cayó con facilidad en firmar dicho informe, sin consultar primero a sus padres consultores, más prácticos que él en los negocios del Paraguay; por esto, y por haber apoyado el informe del gobernador sin consulta alguna, como constó con la llegada del marqués de Valdelirios, convocaron su congreso provincial para deliberar lo que debian ejecutar en caso tan delicado, y en él determinar lo que debia hacerse y si representarian al Rey el manifiesto 
engaño que se hacía a España, ejecutando el cambio intentado, e indemnizar a su Provincial de lo hecho por haber sido manifiestamente engañado.

Prevalecieron los votos de representar al Rey por medio de su Procurador General en Madrid. La suma desproporción y desigualdad que había de la colonia del Sacramento a las Siete Colonias, ya pobladas años hace y de fieles vasallos suyos, y católicos fervorosos, y que eran dignos de que su Majestad los amparase por su lealtad, por su cristiandad y por haber servido a Su Majestad en las guerras que en años pasados tuvieron con los portugueses del Brasil que intentaron sorprender estas mismas colonias.

Todo esto determinaron en su Congregación añadiendo que cediendo Su Majestad Católica las Siete dichas Colonias a favor de los portugueses, venia no solamente a introducirlos en la América Meriodinal sino también a privarse de más de treinta mil súbditos que haciendo este cambio ciertamente se perderían, por que no es creible el aborrecimiento que tienen a los portugueses por los daños que de ellos han recibido y precisarles ahora o a vivir con ellos como esclavos suyos o a desamparar sus tierras, sus casas, sus ganados, sus haciendas y ajuares que ellos con su industria y sudor han adquirido, precisarles ahora a dejarlo todo en mano de los portugueses era un lance que primero perderán la vida, que no lieguen a ejecutarlo, y primero se retirarán a los montes que no están bajo el dominio portugués. A más de esto se descubre aqui otra máxima, que portugueses e ingleses llevan, y es: que una vez apoderados de estas Siete coIonias tienen franca la navegación de los ríos que corren desde el Brasil al Mar de Buenos Aires, ya también al Potosi y provincia del Perú que está en los confines del Paraguay, y a quién sabe si su idea es introducirse en las inmediaciones del Potosí para apoderarse de él. Y más corriendo de alli un río que desagua en el río de la Plata, donde armando unas pequeñas embarcaciones (cosa aqui tan fácil por la mucha madera que hay) que con poco trabajo y en pocos días pueden hallarse sobre el Potosi; ello hoy se mira como ajeno de suceder, aun en la especulativa, pero en estado de poderse practicar y vemos cuantos vivimos en estas partes quiera Dios que sus proyectos no miren a este fin.

Las observaciones que aqui se hacen sobre esto, a eso se encaminan; la solicitud y anhelo de entrar a poseer estas Siete colonias los portugueses a eso se encaminan. Los reconocimientos que han hecho acompañados de ingenieros ingleses muy de antemano, lo persuaden.

El querer destruir con tanta ansia esta barrera que les sirve de embarazo a los portugueses para no poder pasar adelante ellos y los amigos ingleses; cuasi lo haré creible el que quieren apoderarse de el Potosí; que asi fuese, se veía privada España, de sus tan ricas minas, todo es digno de consideración de la más seria reflexión de Su Majestad.

Esta representación concebida en estos y semejantes términos, se determinó representar por la Congregación de la Compañía de Jesús, la que vimos en Madrid, remitida de allá a su Procurador General de Indias que reside en la Corte a fin de que la presentase a Su Majestad cuando se hallare en Consejo, como lo hizo. 
A este tiempo llegaron al Paraguay los comisarios portugueses acompañados de algunos ingenieros ingleses, para establecer los confines proyectados, para poner en práctica el cambio ya tratado entre la Corona de España y la de Portugal; todos tomaron la ruta a los confines del Brasil en compañia de Valdelirios y de los comisarios, con los ingenieros que debian tirar la línea divisoria, que la tomaron tan a satisfacción de los portugueses que ellos jamás pudieron persuadirse que España consintiese tanto, pues le tomaron al Paraguay 500 leguas de terreno, y entre ellas los Siete lugares ya mencionados que era el principal blanco de las ideas portuguesas e inglesas. Apenas se divulgó el hecho en los siete lugares y que les sujetaban al dominio portugués y que el rey de España les desmembraba de su Corona, tomaron su acuerdo los principales caciques de las Colonias y convocaron una Junta General en San Nicolás, lugar grande colocado en el centro de todos, y resolvieron tomar las armas para oponerse a los portugueses, si acaso intentaban la posesión de dichos lugares, y al mismo tiempo despacharon una embajada al gobernador de Buenos Aires en que representaron los méritos contraidos con su Rey en la última guerra entre la España y la Inglaterra, y más en especial en las habidas con los portugueses, cuando sus antepasados sirvieron en el sitio de la Colonia del Sacramento hasta su rendición, y esto a sus costas sin que al Rey le costase un maravedi. Finalmente protestaron la fuerza y determinaron morir antes que ser vasallos de Portugal, y viendo que no se les daba la respuesta categórica que esperaban, pusieron en ejecución lo que se tenian meditado, de tomar las armas y a todo trance defender sus tierras de los portugueses para lo que se juntaron dos mil y quinientos paraguayos en la Colonia de San Nicolás, desde donde pasaron a los confines del Brasil, obligando a los comisarios portugueses e ingleses a que se retirasen sin concluir de asentar la división comerizada.

De este hecho tomó el fundamento que tanto cundió en la europa de la fábula de el Rey Nicolás, y que tanto ruido metió entre los desocupados (...) 4).

(Archivo de la Prov. de Toledo de la Compañia de Jesús. Varios. M-180, doc.

c) Ruptura de las relaciones diplomáticas entre Portugal y Roma (14 junio, 1760)

Carta que de orden de Su Majestad Fidelísima escribió el Secretario de Estado D. Luis de Acuña al Cardenal Nuncio de Portugal para salir de la Corte de Lisboa.

Eminentísimo y reverendísimo Señor:

Su Majestad usando del justo Real supremo motivo y poder que por todos los derechos le compete para conservar ilesa su Regia autoridad y preservar a sus vasallos de escándalos perjudiciales a la tranquilidad pública de sus reinos, me manda intimar a $V$. Eminencia que luego inmediatamente a la presentación desta carta haya $V$. Eminencia de salir de esta Corte para esta banda del Tajo, y haya de salir vía recta de estos reinos en el preciso término de cuatro días. 
Para el decente transporte de $\mathrm{V}$. Eminencia se hallan prontos los esquifes reales en la playa frente de las casas de la habitación de $V$. Eminencia.

$Y$ para que $V$. Eminencia pueda entrar en ellos y seguir su viaje y camino sin recelo alguno de insultos contrarios a la protección de S.M. quiere siempre que en todos los casos haya en sus dominios la inmunidad del carácter de que $V$. Eminencia se halla revestido. Manda el dicho señor al mismo tiempo que acompañe a $V$. Eminencia hasta la frontera de este reino una decorosa y competente escolta militar.

Quedo de V. Eminencia con el mayor obsequio. Dios guarde a V. Eminencia. En Palacio a 14 de junio de 1760. De V. Eminencia obsequisimo servidor. D. Luis de Acuña.

Información que se mandó a Francisco de Almada de Mendoza, Ministro Plenipotenciario de Su Majestad Fidelisima en la Curia de Roma para participar al Papa la noticia del procedimiento que S.M. había ordenado se tuviese con el Cardenal Acciaioli, Nuncio en Portugal.

(Archivo de la Prov. de Toledo. De la Compañía de Jesús. Varios, M-31, doc. 8).

d) Ruptura de las relaciones diplomáticas de Portugal con Roma. 1760

(Resumen del proceso)

PRIMER DECRETO DEL MINISTRO DE PORTUGAL

Hago saber a todos los vasallos del Rey Fidelísimo que habiendo éste visto de mucho tiempo con notable constancia por una serie de hechos decisivos del ministerio de Roma, por medio del cual se conducen a Su Santidad las instancias de S.M. como la expuesta de tan repetidas connivencias siempre desaprobadas, no le prometa concebir esperanza de poder dirigir sus suplicas a la presencia del Smo. Pontífice y viendo que la extraordinaria, escandalosa y jamás vista animosidad del ministerio ha pasado al exceso de declararse una abierta rutura a la Majestad Fidelisima por hacerse imposible en estas indecorosas circunstancias conservar en Roma un Ministro súbdito y un número de vasallos que no serian más que testigos de los insultos que contra su decoro se van acumulando y aumentando en palabras y escritos cada día con más libertad del dicho Ministro y de sus declarados y notorios secuaces que ha agregado a su partido con escándalo universal de toda la Europa; se ve obligado el Rey Fedelísimo a mandar salir súbito con su Ministro todos sus vasallos y cuantos gozan beneficio eclesiástico en sus dominios de una corte, donde sin poder servir al Smo. Pontifice agravan cada hora con su presencia los actos lesivos, y a S.M. que debe conservar su autoridad tan ilesa e independiente en lo temporal cuanto se la dejaron sus Augustos prodecesores sin ser responsable más que a Dios y a la Iglesia Católica de la que es y será siempre devoto hijo y ejemplarisimo defensor. Julio, dos, Francisco Almada. 
SEGUNDO DECRETO

Hago saber a los vasallos del Rey Fidelísimo que habiendo Su Santidad conocido cuán importante era que el Ministro de S.M. continuase la comunicación con el Ministro de S. Santidad del que S.M. se halla tan seriamente quejoso, fue servido el Smo. Pontifice deputar con total exclusión de dicho Ministro al Cardenal Corsini, protector de Portugal, para conferir con dicho Ministro, y como por esa deputación se abrirá nuevo y seguro camino de que el Rey obtenga las satisfacciones que se le deben con tanta presteza como se requiere, arbitro a dicho Ministro a tomar sobre si si el Smo. Pontifice se acuerda de un Monarca asesinado en su corte por maquinaciones probadas y juzgadas de una congregación de su instituto dedicado a Dios, y de un Rey, que siempre tan execrando desacato es gravisimamente ofendido más ha de un año en la misma Roma con agravios y calumnias que pondrian en el último término a cualquier hombre particular, y si se mueve Su Santidad a dar a S.M. las merecidas y necesarias satisfacciones que S. Majestad espera. Julio, 4. Francisco Almada.

El Ministro de Portugal presentó el dia 30 de junio al Cardenal Cavalccini una memoria en que se lamenta de la Corte de Roma de que no se haya depuesto acá el obispo de Bahia, rebelde al Rey y de que no es creido el Rey sobre los delitos de los jesuitas.

Dice también en la Memoria que no quiere el Rey de Portugal Nuncio con jurisdicción y que esta sede debe ir al Patriarcado de Lisboa. Que se amplió el Breve de visitados y reformador que se dio al Cardenal Saldaña sobre los jesuitas, para que visite y reforme los demás religiones; que la minuta del Breve (no se dio tal Breve) para jużgar los eclesiásticos reos, es del gusto de la Corte, pero que se ha de ampliar para siempre y no ha de ser solo para uno.

Pidió después audiencia al Papa el Ministro de Portugal, se la dilató y al fin se la negó. Publicó en este Hospital de Portugueses el primer decreto de ruptura, y por una equivocación con el Eminentísimo Corsini formó el segundo Decreto. El día seis se le intimó de orden del Papa que saliese de la Corte y del Estado. El día siete a media noche salió de Roma camino de Toscana.

Dejó un manifiesto de quince pliegos distribuidos a los embajadores para que las remitiesen a sus Cortes en que decia las razones de su Corte para la ruptura de Roma: el cual, aseguran, está injuriosisimo contra Roma, los Cardenales y el Papa.

El TeRCer Decreto indicaba que todos los portugueses salieran de Roma en el término de dos meses.

(Resumen de decretos y noticias traducido al castellano. Archivo de la Prov. de Toledo de la Compañía de Jesús. Varios, C-317, 19). 